San Jose State University

SJSU ScholarWorks

Master's Theses

Master's Theses and Graduate Research

1999

\title{
Tidal scour and its relation to erosion and sediment transport in Elkhorn Slough
}

Christopher Mario Malzonen

San Jose State University

Follow this and additional works at: https://scholarworks.sjsu.edu/etd_theses

\section{Recommended Citation}

Malzonen, Christopher Mario, "Tidal scour and its relation to erosion and sediment transport in Elkhorn Slough" (1999). Master's Theses. 1826.

DOI: https://doi.org/10.31979/etd.zz9e-ww37

https://scholarworks.sjsu.edu/etd_theses/1826

This Thesis is brought to you for free and open access by the Master's Theses and Graduate Research at SJSU ScholarWorks. It has been accepted for inclusion in Master's Theses by an authorized administrator of SJSU ScholarWorks. For more information, please contact scholarworks@sjsu.edu. 


\section{INFORMATION TO USERS}

This manuscript has been reproduced from the microfilm master. UMI films the texi directly from the original or copy submitted. Thus, some thesis and dissertation copies are in typewriter face, while others may be from any type of computer printer.

The quality of this reproduction is dependent upon the quality of the copy submitted. Broken or indistinct print, colored or poor quality illustrations and photographs, print bleedthrough, substandard margins, and improper alignment can adversely affect reproduction.

In the unlikely event that the author did not send UMI a complete manuscript and there are missing pages, these will be noted. Also, if unauthorized copyright material had to be removed, a note will indicate the deletion.

Oversize materials (e.g., maps, drawings, charts) are reproduced by sectioning the original, beginning at the upper left-hand corner and continuing from left to right in equal sections with small overlaps. Each original is also photographed in one exposure and is included in reduced form at the back of the book.

Photographs included in the original manuscript have been reproduced xerographically in this copy. Higher quality 6" $x$ 9" black and white photographic prints are available for any photographs or illustrations appearing in this copy for an additional charge. Contact UMI directly to order.

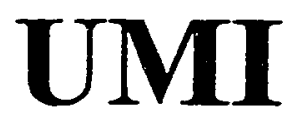

A Bell \& Howell Information Company 
- 
NOTE TO USERS

This reproduction is the best copy available

UMI 

TIDAL SCOUR AND ITS RELATION TO EROSION AND SEDIMENT TRANSPORT IN ELKHORN SLOUGH

\author{
A Thesis \\ Presented to \\ The Faculty of the Department of Geology \\ San Jose State University \\ In Partial Fulfillment \\ of the Requirements for the Degree \\ Master of Science
}

By

Christopher Mario Malzone

May 1999 
UMI Number: 1394538

\section{Copyright 1999 by \\ Malzone, Christopher Mario}

All rights reserved.

UMI Microform 1394538

Copyright 1999, by UMI Company. All rights reserved.

This microform edition is protected against unauthorized copying under Title 17, United States Code.

\section{UMI}

300 North Zeeb Road

Ann Arbor, MI 48103 
(C) 1999

Christopher Mario Malzone

ALL RIGHTS RESERVED 
APPROVED FOR THE DEPARTMENT OF GEOLOGY

Woald 2. Peed

Wilham Broentow

$\frac{\text { I mize } W \text { framer }}{\text { David W. Andersen }}$

APPROVED FOR THE UNIVERSITY

William Fisk 


\begin{abstract}
TIDAL SCOUR AND ITS RELATION TO EROSION AND SEDIMENT TRANSPORT IN ELKHORN SLOUGH
\end{abstract}

by Christopher M. Malzone

Elkhorn Slough is a shallow-water embayment that is part of a $585-\mathrm{km}^{2}$ watershed at the easternmost extent of the Monterey Bay in California. In 1947, the shoreline dunes along its western marsh were breached for the expansion of the Moss Landing Harbor. This action provided open access to coastal waters, which initiated a tidal scour process that has widened the main channel and eroded the banks of the slough. Field measurements of bathymetry, bank erosion, tidal and hydrologic characteristics, and sediment transport were undertaken from 1993 to 1996 . These data were compared to results of previous studies to evaluate the erosive processes currentiy operating in Elkhorn Slough and their temporal evolution.

The results of this study show that a $55 \%$ increase in water volume has led to high current velocities (up to $1.47 \mathrm{~m} / \mathrm{s}$ ) and high average rates of sediment loss $\left(8 \times 10^{4}\right.$ $\mathrm{m}^{3} / \mathrm{yr}$ ). If the present conditions continue, Elkhorn Slough will evolve into a shallowwater tidal embayment with its primary habitats being an extensive lower-intertidal mudflat and subtidal main channel in 40 to 120 years. 


\section{ACKNOWLEDGEMENTS}

This manuscript represents not only several years of leaming and hard work but a lifestyle devoted to science, nature and understanding. I would like to thank all those who helped maintain and support this lifestyle. Above all, the faculty, staff and students at Moss Landing Marine Laboratories whose input, support and generosity have been unparalleled. The Monterey Bay National Marine Sanctuary and the Elkhom Slough Foundation for funding this project and my thesis advisors for their patience, advice and above all for their time in reviewing and commenting on this document.

My special appreciation goes out to Dr. Broenkow at Moss Landing Marine Labs whose countless hours allowed me to conceptualize, understand and conquer the complexity of my tasks. Finally, thanks to my family and friends for just being there. 
INTRODUCTION

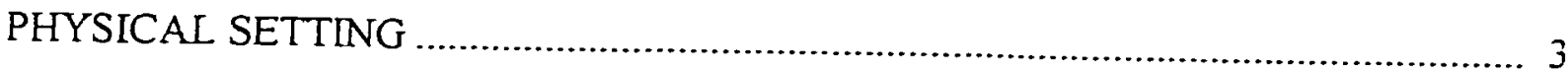

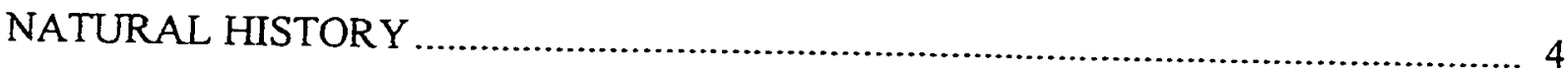

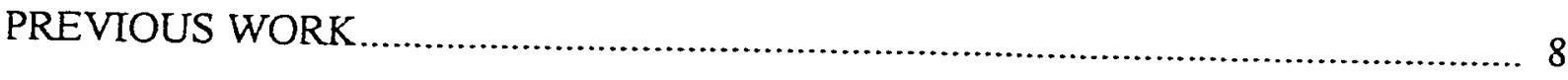

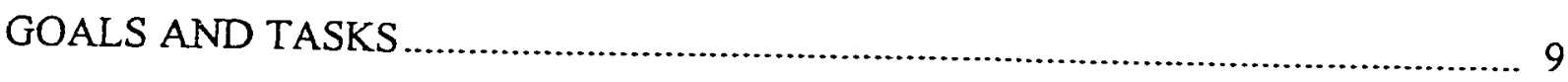

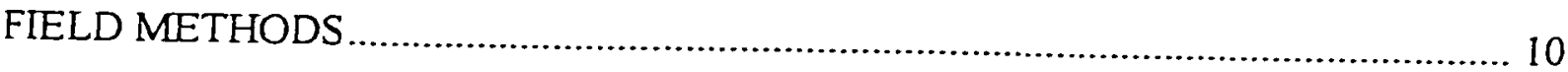

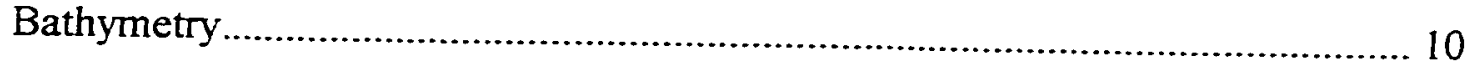

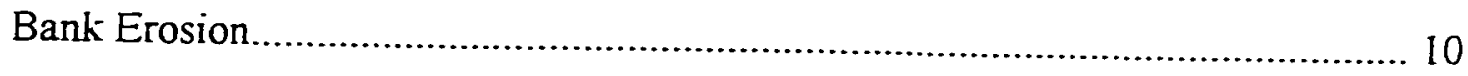

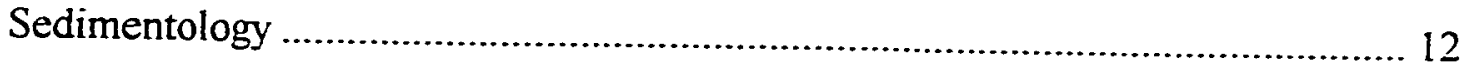

Tidal Height Characteristics ................................................................... 15

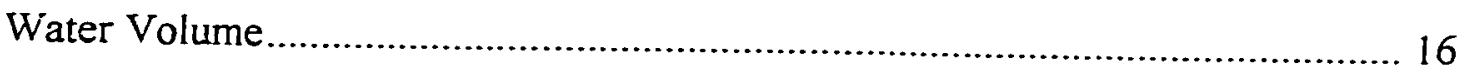

Hydrology and Suspended Sediment Profiling ................................................ 17

Longterm Hydrologic and Suspended Sediment Monitoring .............................. 19

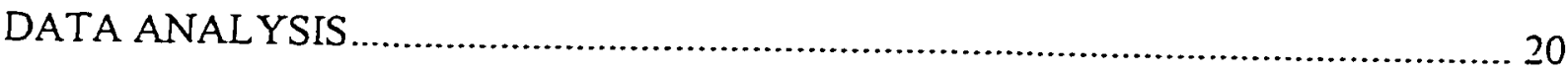

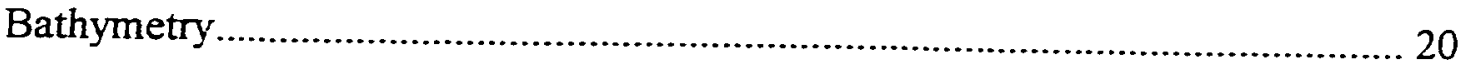

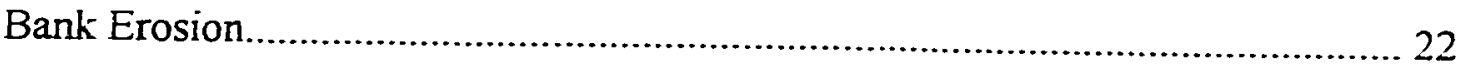

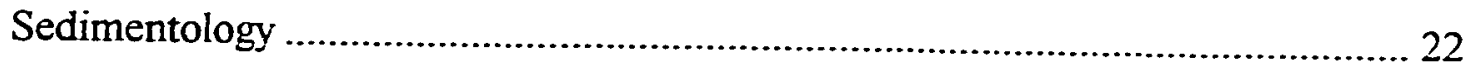

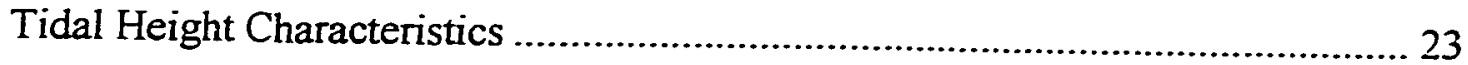


Tidal Height Characteristics ..................................................................... 23

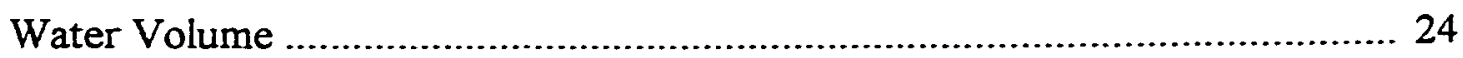

Hydrology and Suspended Sediment Profiles .................................................. 24

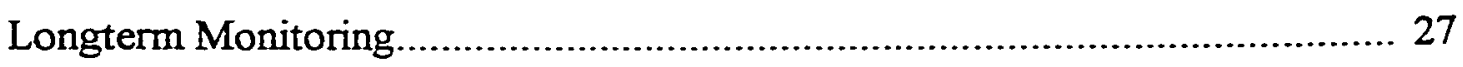

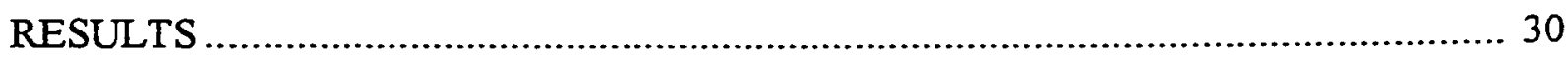

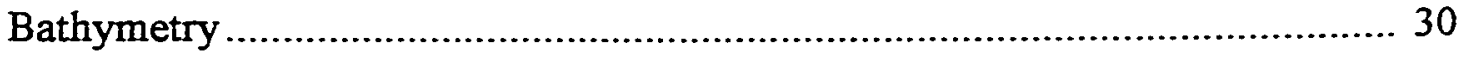

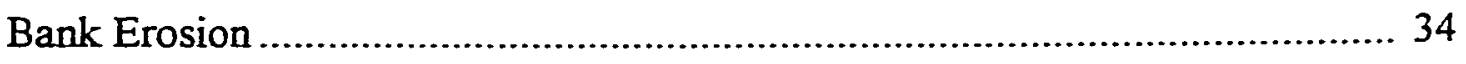

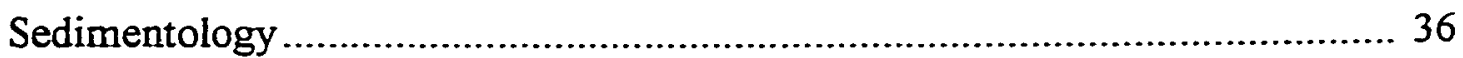

Tidal Height Characteristics......................................................................... 41

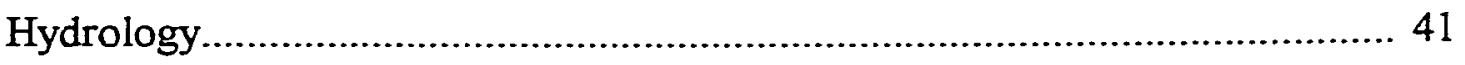

Suspended Sediment Transport .................................................................... 49

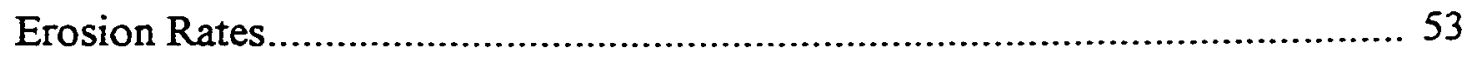

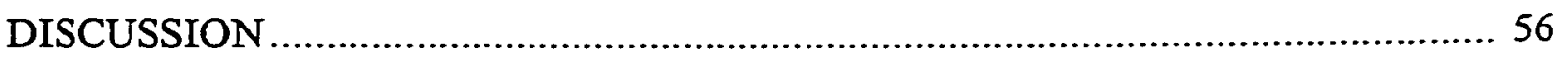

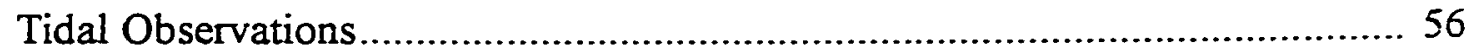

Temporal Changes in Hydrology ............................................................... 57

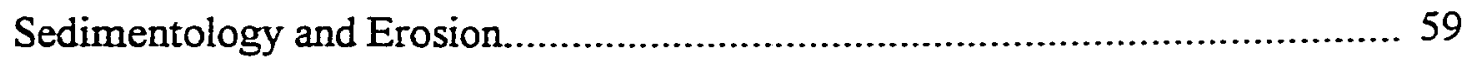

Evolution in Slough Morphology ................................................................ 61

Erosion Rates and Future Sediment Losses .................................................. 66

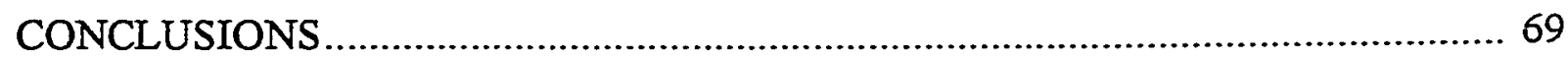

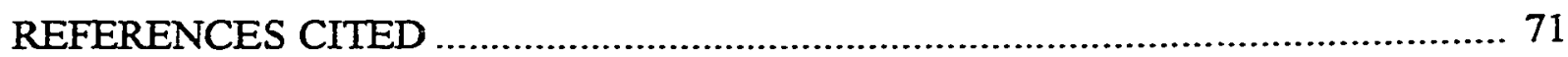




\section{LIST OF ILLUSTRATIONS}

Figure

Page

1. Aerial Photograph of the Elkhorn Slough Area Showing Major Points of Reference

2. Sketch Maps Depicting Changes in the Geomorphology of Elkhorn

Slough

3. Elkhorn Slough Showing Locations of Bathymetric Survey Lines for November and December Surveys

4. Elkhom Slough Showing Locations of Air Photo Transects Used to Calculate Bank Erosion/ Saltmarsh Erosion Rates, Sediment Sampling Transects, Hydrological Monitoring Stations and Tide Gauges

5. Elkhom Slough Showing Location of Tidal Scour Stations Used to Calculate Bank and Salt Marsh Erosion from April 1994 and April 1996

6. Cross-section of Elkhorn Slough at the Highway One Bridge Showing Locations of Current and Suspended Sediment Profiling Stations. Inset Graph Shows Cross-sectional Area as a Function of Depth

7. Schematic Drawing of a Transmissometer Collimated Optical System Similar to the One Used During This Study.

8. Graphs of Attenuation Versus TSM Used in Calibration of the Transmissometer

9. a) Profile of Elkhorn Slough Main Channel with Important Landmarks

b) Cumulative Volumes of Elkhorn Slough with Distance Inland

10. Comparison of 1988 and 1993 Main Channel Depth Profiles at 5 Locations along the Length of Elkhorn Slough.

11. Comparison of 1988 and 1993 Channel Depth Profiles in Parson's Slough 
Figure

12. Annualized Rates of Bank Migration in Elkhorn Slough

13. Sediment Analysis Results Showing Wet and Dry Densities as well as Porosities for Marsh, Mudflat and Channel Sediments

14. Spring and Neap Tidal Regimes in Elkhorn Slough

15. Harmonic Regression Results for Analysis of May 1995 Tidal Height

Data

16. Spring and Neap Fluctuations in Tidal Height, Water Volume and Current Speed

17. Elkhorn Slough Showing Recent Additions to the Total Water Volume and Wetted Surface Area as well as the Percent Contributions for Each to the Total Slough System

18. Cumulative Water Volumes for the Three Monitoring Stations at the Highway One Bridge

19. a) Polar Plot of Current Velocity as a Function of Flow Direction

b) Map of the Lower Slough With Vectors Indicating the Different Directions of Flow

20. Top: Current Velocity Profile at the Mouth of Elkhorn Slough.

Bottom: Turbidity Profile at the Mouth of Elkhorn Slough

21. Cumulative Flux, Transport of Suspended Material, and Tidal Height for 14 to 24 July 1994

22. Average annual Gains and Losses from the Elkhorn Slough Regions ...... 54

23. dH/dT Versus U max. for 3 Data Sets; Clark, Wong and This Study ...... 58

24. Illustration of Channel Adjustment to Scour and Fill ................................ 62

Plate

1. Hydrography and Saltmarsh Area, Elkhom Slough, California ..... in pocket 


\section{LIST OF TABLES}

Table

1. Reference Bench Marks and Associated Datum Used for Leveling of Tide Gauges

2. Subtidal and Lower-intertidal Erosion Rates Based on Changes from 1988 and 1993 Cross-sectional Data.

3. Bank Migration Measurements from 1994 to 1996

4. Recent Additions to the Elkhorn Slough System Contributing to Water

Volume Increases and Saltwater Incursion.

5. Available Erodable Surface Areas Based on Locations in Elkhorn Slough 64 


\section{INTRODUCTION}

Wetland ecology along the central California coast has been impacted by human intervention. Morro Bay ( $-300 \mathrm{~km}$ south of the Monterey Bay), Bolinas Lagoon ( -240 $\mathrm{km}$ north of Monterey Bay) and Elkhorn Slough (along the Monterey Bay) are similar systems with tidal channels, mudflats and marshes, all of which support a rich diversity of marine and estuarine life, as well as providing homes to small boat harbors, urban development and tourism (Fig. 1). These waterways are sensitive to ecological change, especially that caused by human activities, necessitating intensive management and conservation planning. Bolinas Lagoon and Morro Bay have been classified as depositional systems with threats to their existing habitats resulting from siltation (Haltiner and Thor, 1991). In contrast, habitat loss in Elkhorn Slough is due to erosion of the main channel, banks and tidal creeks (Oliver et al., in review). Resource management and habitat conservation in the Elkhorn Slough are complicated by the fact that the geological record shows no comparable analog from which predictions of future habitat alterations may be made.

This thesis is a synthesis of bathymetric, bank erosion, tidal, hydrologic and sediment transport data collected within the slough from 1993 to 1996, for the purpose of providing insight regarding future habitat changes. All data have been compared to results of previous studies to evaluate temporal change due to erosive processes in Elkhorn Slough. 


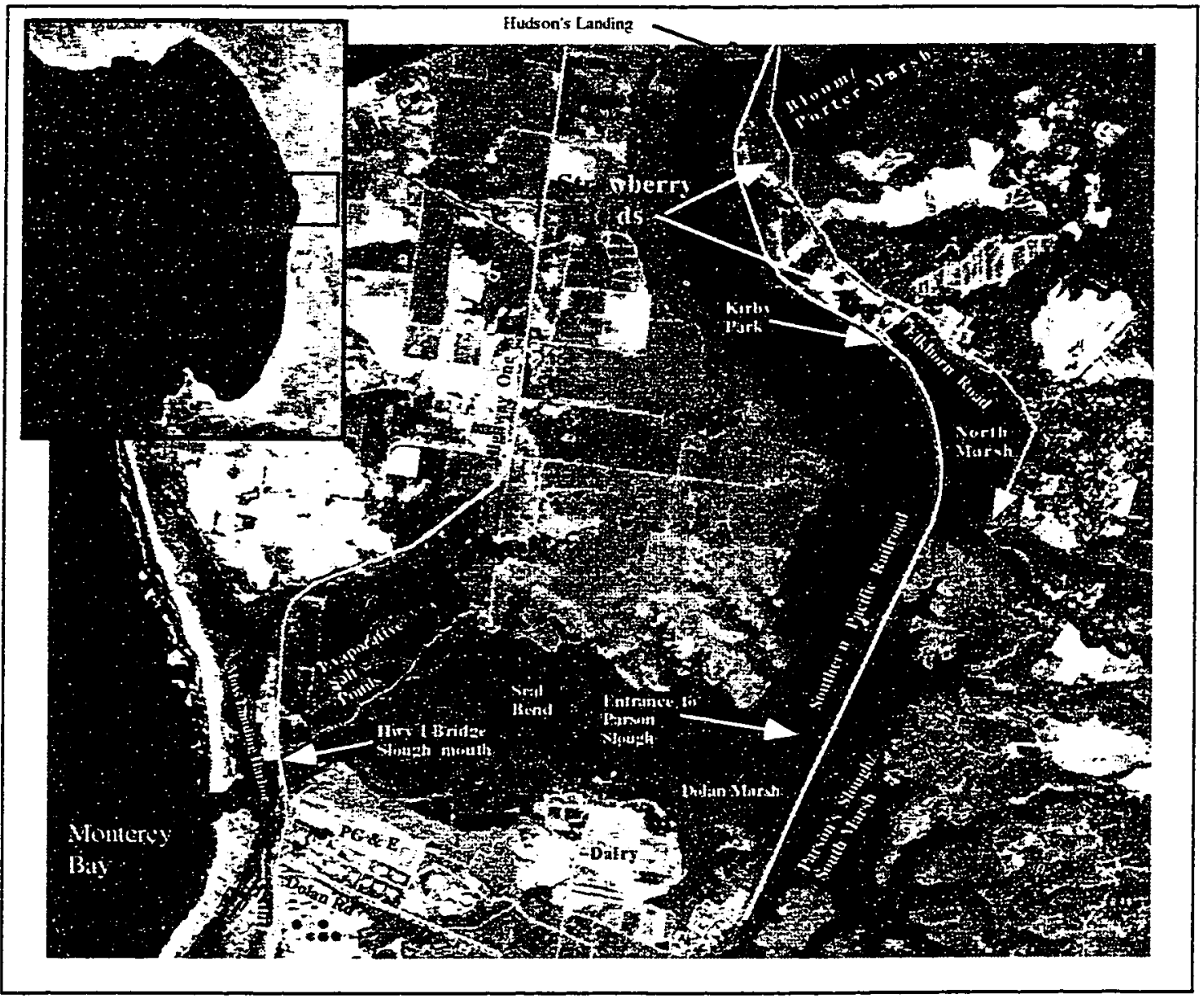

Figure 1. Aerial photograph of $31 \mathrm{~km}^{2}$ of the Elkhorn Slough area showing major points of reference. Inset picture shows the location of Elkhorn Slough within the Monterey Bay. 
PHYSICAL SETTING

Elkhorn Slough is a tidal embayment at the easternmost extent of the Monterey Bay in Califomia that is surrounded by a $585-\mathrm{km}^{2}$ watershed (Fig. 1). The mouth of the slough is situated just inland of the Moss Landing Harbor mouth with the main slough channel meandering for a distance of $10 \mathrm{~km}$ to the northeast. There are 5 main tributary embayments connected to Elkhorn Slough: evaporative salt ponds, Dolan Marsh, Parson's Slough/ South Marsh, North Marsh, and Bloom/ Porter Marsh. Habitats of the shallowwater embayment can be divided into three distinct zones: subtidal, lower intertidal and upper intertidal (Weimer et al., 1982). The subtidal zone encompasses the entire main channel and the lower portion of the mudflat with the upper boundary located at mean low water $(<0.33 \mathrm{~m})$. The lower-intertidal zone occupies the area between mean low water and mean high water $(0.33 \mathrm{~m}$ to $1.46 \mathrm{~m})$, including the majority of the mudflais and fringes of the Salicornia marsh. The upper-intertidal area, located above mean high water, contains the Salicornia marsh habitat. All three zones are subject to tidal action with the saltmarsh and mudflat regions being heavily dissected by tidal creeks and the main channel covered with clay and clam shell debris. 


\section{NATURAL HISTORY}

The formation of Elkhorn Slough began during late Pliocene to early Pleistocene time as large rivers draining from the Santa Clara Valley and, at times, the San Joaquin Valley eroded through the Aromas Sands in Elkhorn Valley (Schwartz, 1983). During the late Pleistocene, tectonic activity along the San Andreas and Zayante fault zones disrupted this drainage through uplift and tilting of the land surface, resulting in the displacement of the northern portions of the Elkhorn Valley watershed to form the Pajaro River system (Schwartz, 1983). Subsidence, following fluvial scour and tectonic displacement, resulted in marine sedimentation within a seasonal estuary beginning 8000 years ago.

In the 1800 's, the wetlands surrounding Elkhom Slough were converted to agricultural lands (Smith, 1973). Between 1876 and 1880, the Southern Pacific Railroad built a main interstate line along the east side of the slough, isolating large areas of salt marsh from tidal action (Fig. 2a). Around the turn of the century a $1.5-\mathrm{km}^{2}$ region near the mouth of the slough was developed into evaporative salt ponds (Gordon, 1974). Before 1908, the Salinas River provided fresh water to the estuary as it flowed $8.8 \mathrm{~km}$ north of its present mouth (Fig. 2a). The mouth of the Elkhorn Slough-Salinas River system was located $1.6 \mathrm{~km}$ north of the present Highway One bridge. During summer, a sandbar formed seaward of the Elkhorn Slough-Salinas River mouth, depriving the slough of salt water. During winter, increased precipitation and runoff led to a breach of this sandbar allowing water exchange between the ocean and the slough (MacGinitie, 

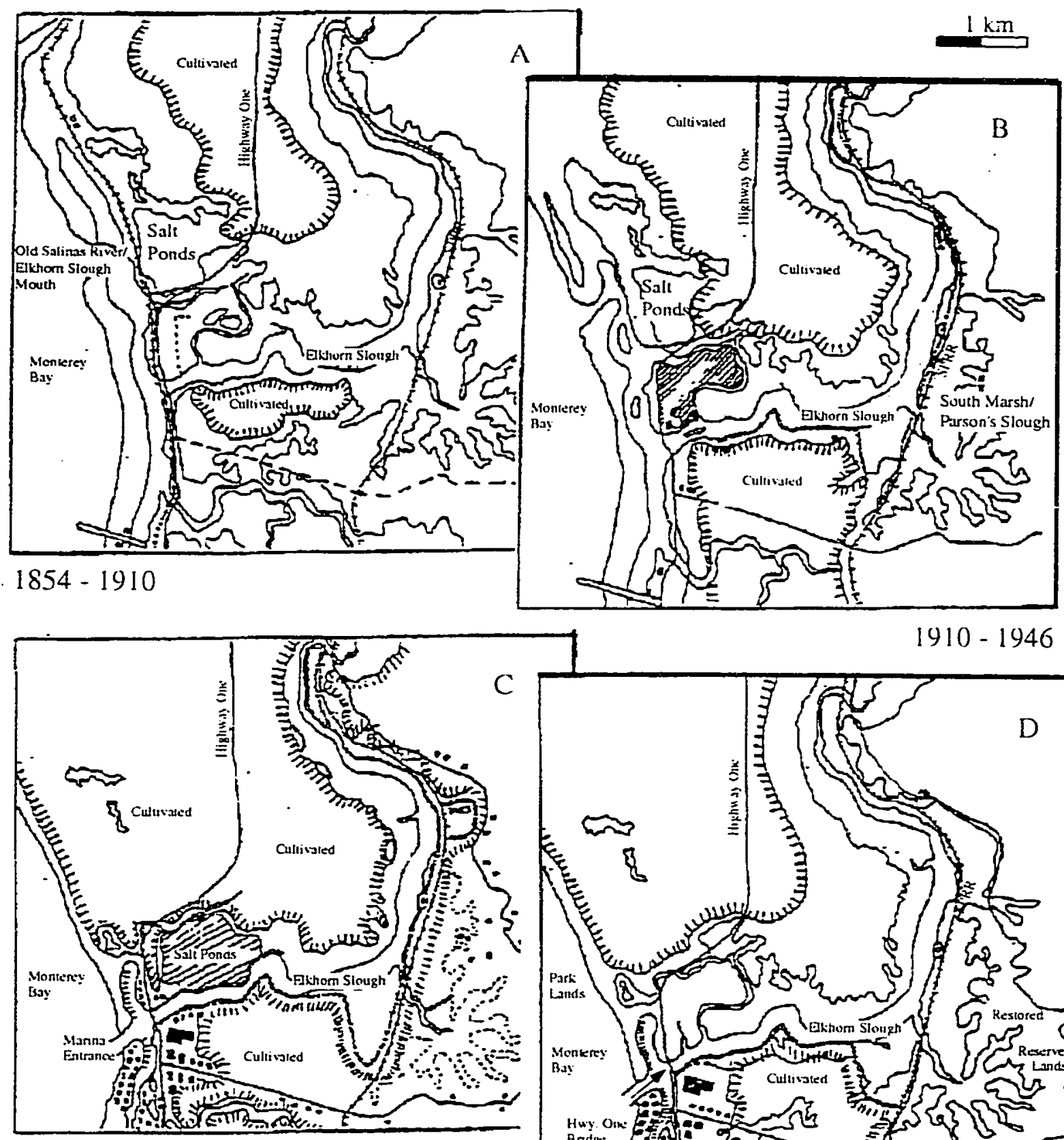

$1946-1977$
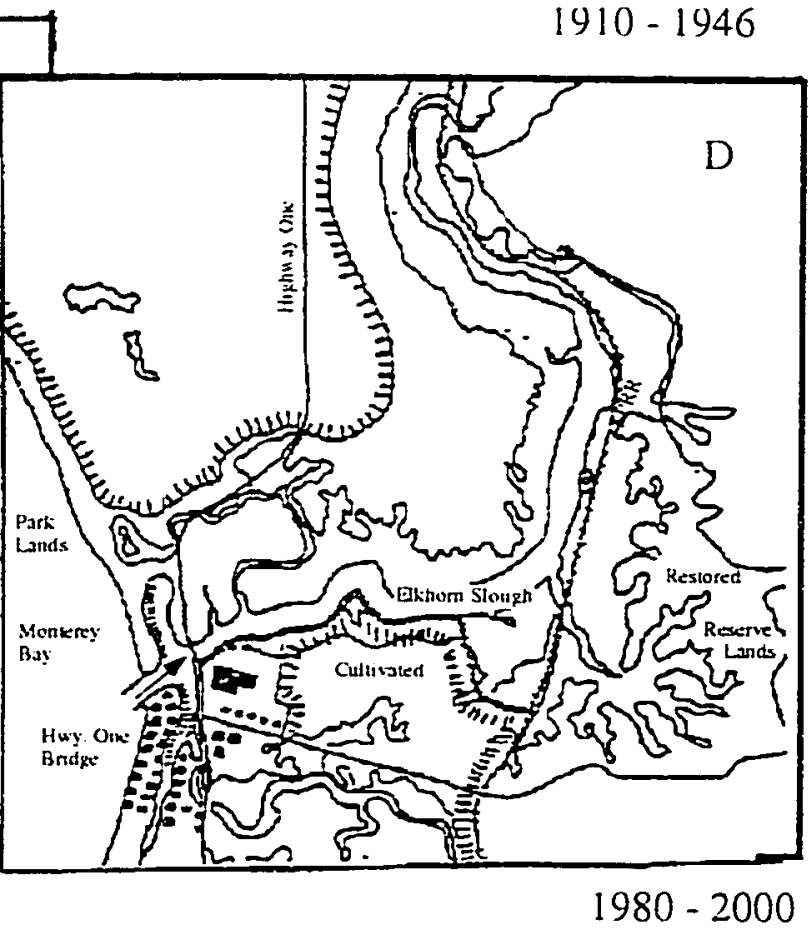

Figure 2. Sketch maps depicting changes in the geomorphology of Elkhorn Slough. SPRR = Southern Pacific Railroad(Courtesy of Mark Silberstein. Elkhorn Slough Foundation). 
1935; Gordon, 1974). In 1908, the dunes, located $6.6 \mathrm{~km}$ south of Moss Landing, were excavated allowing the Salinas River to drain directly into the Monterey Bay. An earthen dike, constructed across the Salinas River north of the new river mouth, permanently deprived Elkhom Slough of a major source of fresh water and sediment (Gordon, 1974) (Fig. 2b).

Between 1910 and 1946, additional wetlands and tidal creeks were converted to pasture, and plans were drawn up to expand Moss Landing harbor to allow for increased boat moorage (Gordon, 1974). The harbor expansion plan made use of the deep waters at the head of Monterey submarine canyon as a safe harbor entrance. The dunes directly in front of the Elkhorn Slough mouth were breached, and by 1947, two jetties were constructed with the axis of the channel aligned to the southwest, thereby providing shelter from prevalent northwest swells (Fig. 2c). Harbor construction is the most significant physical change to affect the slough in this century. Opening the harbor mouth allowed offshore tides to propagate into the slough system, initiating an extensive tidal scour process that continues to this day (Malzone and Kvitek, 1995).

Following harbor construction, plans were made by the Army Corps of Engineers to limit tidal excursion in the slough through the use of water-flow control gates at the Highway One bridge (Fig. 1). This action was never taken and during the past 5 decades local landowners have witnessed increases in channel depth and channel width (Oliver $e t$ $a l .$, in review). Additional dikes and levees were constructed to protect adjacent lands. In 1983, the California Department of Fish and Game was given permission to restore tidal action to $3.40 \mathrm{~km}^{2}$ in the Parson's Slough/ South Marsh area (Fig. 2d). This action 
resulted in the establishment of reclaimed saltmarsh habitat as well as an increase in tidal volume (Wong, 1989). 


\section{PREVIOUS WORK}

Previous studies in Elkhorn Slough have resulted in a good understanding of its physical parameters. Clark (1972) used a simple geometric model of shallow-water embayments to relate the magnitude of tidal currents to the rate of change in water level $(\mathrm{dH} / \mathrm{dT})$. His analyses of current velocity versus $\mathrm{dH} / \mathrm{dT}$ predicted a maximum current velocity of $0.72 \mathrm{~m} / \mathrm{s}$ at that time and established a baseline from which to track future changes in tidal currents. Smith (1973) used a simple three-layer geometry (channel, mudflats and salt marsh) to predict water volumes at different tidal heights in Elkhorn Slough to determine the diffusive flux and residence time of phosphate. Reilly (1978) made current measurements to describe the mechanics of phosphate flux. Wong (1989) measured tidal heights and currents in 1988, and found that current velocities at the Highway One bridge had increased by 55\% since 1972.

Oliver et al. (in review) documented an $8 \%$ annual loss of salt marsh habitat due to the increasing tidal volume and tidal currents in Elkhom Slough between 1980 and 1988. Crampton (1994) compared historical and recent subtidal and intertidal erosion rates to estimate $1.61 \times 10^{6} \mathrm{~m}^{3}$ of sediment loss from the system from 1947 to 1993 . Philip Williams and Associates (1992) assessed the tidal scour problem in the slough and proposed possible solutions, including, the construction of a sill at the mouth of the slough to mute tidal circulation and theoretically alleviate tidal scour. Before building any structure, detailed hydrographic, bathymetric, and erosion data are needed to assess the environmental impact of the proposed sill. 
GOALS AND TASKS

In response to the needs described above and to concerns of local and federal agencies, the study presented here was structured with three main goals:

- To provide baseline bathymetric, hydraulic, tidal and erosion data needed for future studies.

- To determine rates of sediment transport in Elkhorn Slough.

- To determine if the present rate of erosion by tidal scour in the Elkhorn Slough continues to increase or if the slough is approaching equilibrium.

The study was divided into seven tasks to obtain these goals. All involved quantifying a variety of physical parameters in the slough and, whenever possible, comparing the results with those of previous studies to evaluate temporal change. These tasks are: 1) produce the first detailed bathymetric chart of the Elkhorn Slough and evaluate changes in cross-sectional profiles from 1988 (Oliver et al., in review) to 1993 , 2) calculate the present rates of bank erosion along the main channel and tidal creeks, 3) determine if and where erosion rates are changing with time, 4) determine if sediment density and porosity differences occur throughout the length of the slough and if there is a relationship to tidal scour, 5) quantify water volumes, tidal height ranges, current velocities and current velocity profiles at the mouth of the Elkhorn Slough, 6) calculate the change in water volume and surface area from recent alterations to the system as a result of dike and levee breaches, and 7) determine the suspended sediment budget of Elkhorn Slough. 
FIELD METHODS

\section{Bathymetry}

Despite the inclusion of Elkhorn Slough as part of the Monterey Bay National Marine Sanctuary and the National Estuarine Reserve, a detailed bathymetric survey had not been completed prior to this study. Using the bathymetry information from Elkhorn Slough, the geomorphologies of regions subject to lower-intertidal and subtidal erosion were determined.

During November and December 1993, several transect lines, spaced between 75 and $150 \mathrm{~m}$ apart, were run perpendicular to the axis of Elkhorn Slough (Fig. 3). Universal Transverse Mercator (UTM) positions were recorded using a Trimble Navigation 4000RL differential Global Positioning System (dGPS), and water depths were obtained using an Innerspace 448 digital fathometer. Data were acquired at 1-m intervals using the Hypack software by Coastal Oceanographics, Incorporated. The dGPS navigation produced position accuracies of $5 \mathrm{~m}$ in the horizontal plane. Tidal height was recorded using Fischer and Porter tide gauges at the Highway One bridge and Kirby Park during the survey so that the recorded depths could be corrected to mean lower-low water (MLLW) with an established accuracy of $\pm 0.25 \mathrm{~m}$.

\section{Bank Erosion}

Bank erosion studies were undertaken to determine annual rates of loss of salt marsh habitat and increases in channel widths throughout the slough. Air photos of the 


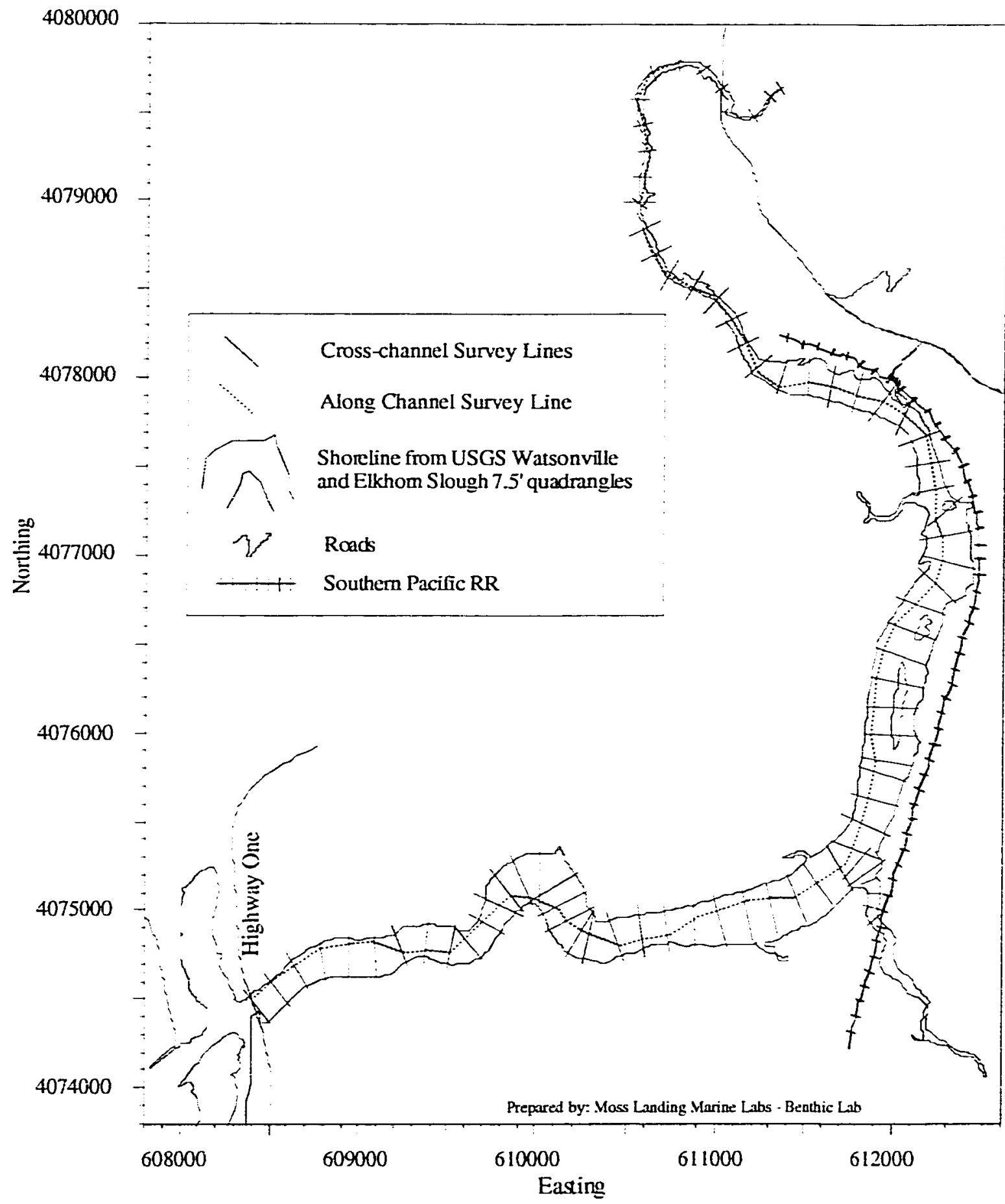

Figure 3. Elkhorn Slough showing locations of bathymetric survey lines for the November and December 1993 surveys. Coordinate system: UTM zone 10. Datum: WGS 84. 
Elkhorn Slough area taken in 1980, 1988 and 1992 were calibrated using known reference points and studied at 19 locations to determine relative changes in the widths of the main channel and adjacent tidal creeks (Fig. 4). In situ measurements of bank erosion were made at 57 stations in the slough from April 1994 to April 1996 (Fig. 5).

At each station, a permanent 10-m transect, marked with two PVC stakes, was established parallel to the shoreline and $2 \mathrm{~m}$ away from the bank edge. At the seaward transect stake, a steel pin was driven into the ground and the location was recorded using dGPS so that, in the event that the PVC stake was lost or vandalized, the station could be relocated using dGPS and pinpointed using a metal detector. Bank erosion rates were determined by measuring the change in position of the bank edge and saltmarsh vegetation edge in relation to the transect line. These measurements were taken in April and October 1994 and April 1996. For each sampling date, mean distances were calculated from 5 measurements acquired at 2-m intervals along each transect line.

\section{Sedimentology}

The nature and magnitude of erosion is dependent on the material of the substrate and its response to scour. In Elkhorn Slough, scour by tidal currents occurs within three distinct environments: upper-intertidal salt marsh, lower-intertidal mudflats and the subtidal main channel. To determine if erosion in these areas is dependent on nature of the substrate, sediment samples were acquired along 6 transects in the slough, in May 1996 , for analysis of density and porosity and to calibrate the beam attenuation 


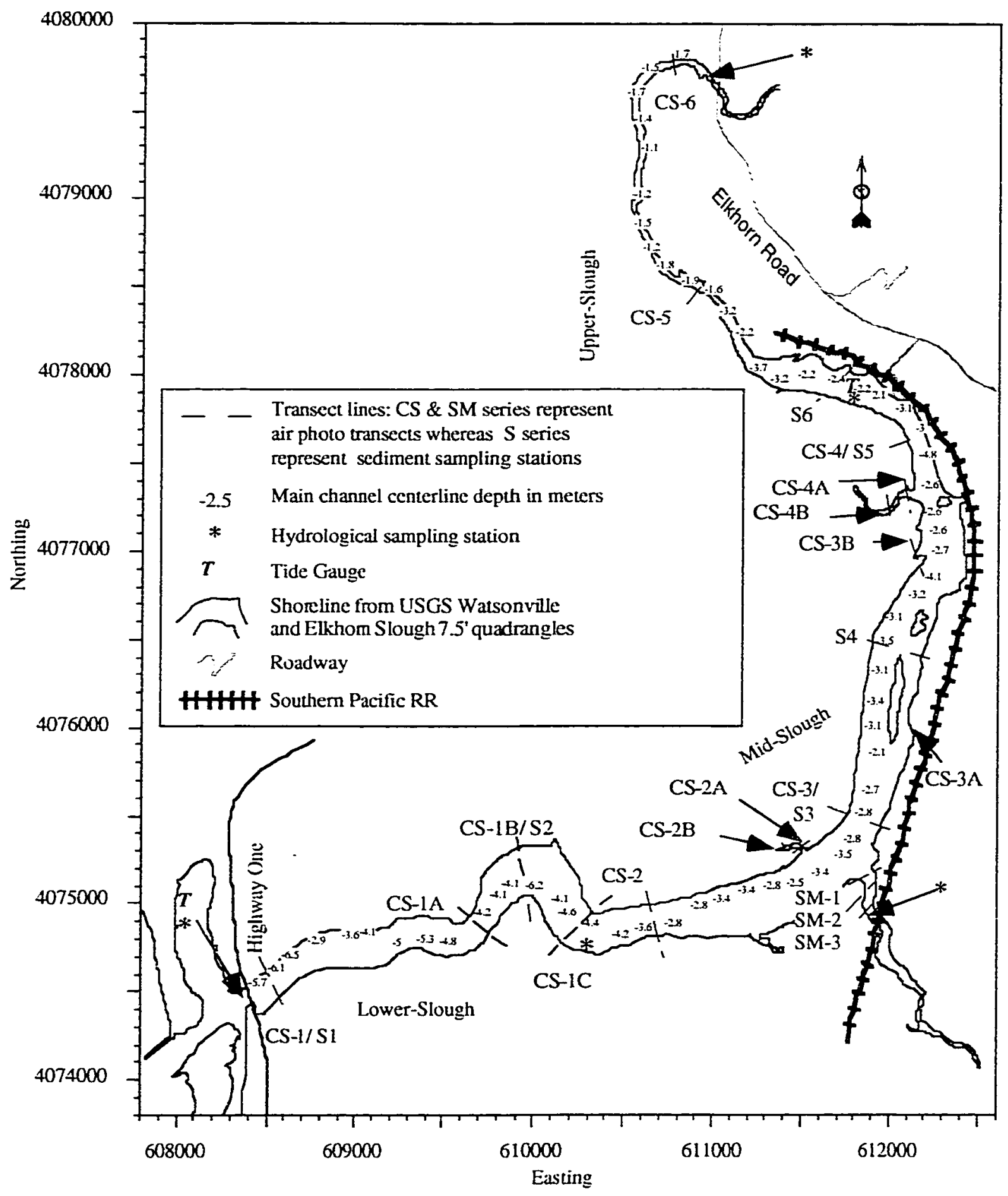

Figure 4. Elkhom Slough showing locations of air photo transects (CS \& SM series) used to calculate bank erosion/ saltmarsh erosion rates, sediment sampling transects (S series), hydrological monitoring stations and tide gauges. Depths are relative to MLLW and based on values obtained during 1993 surveys. Coordinate system: UTM zone 10 . 


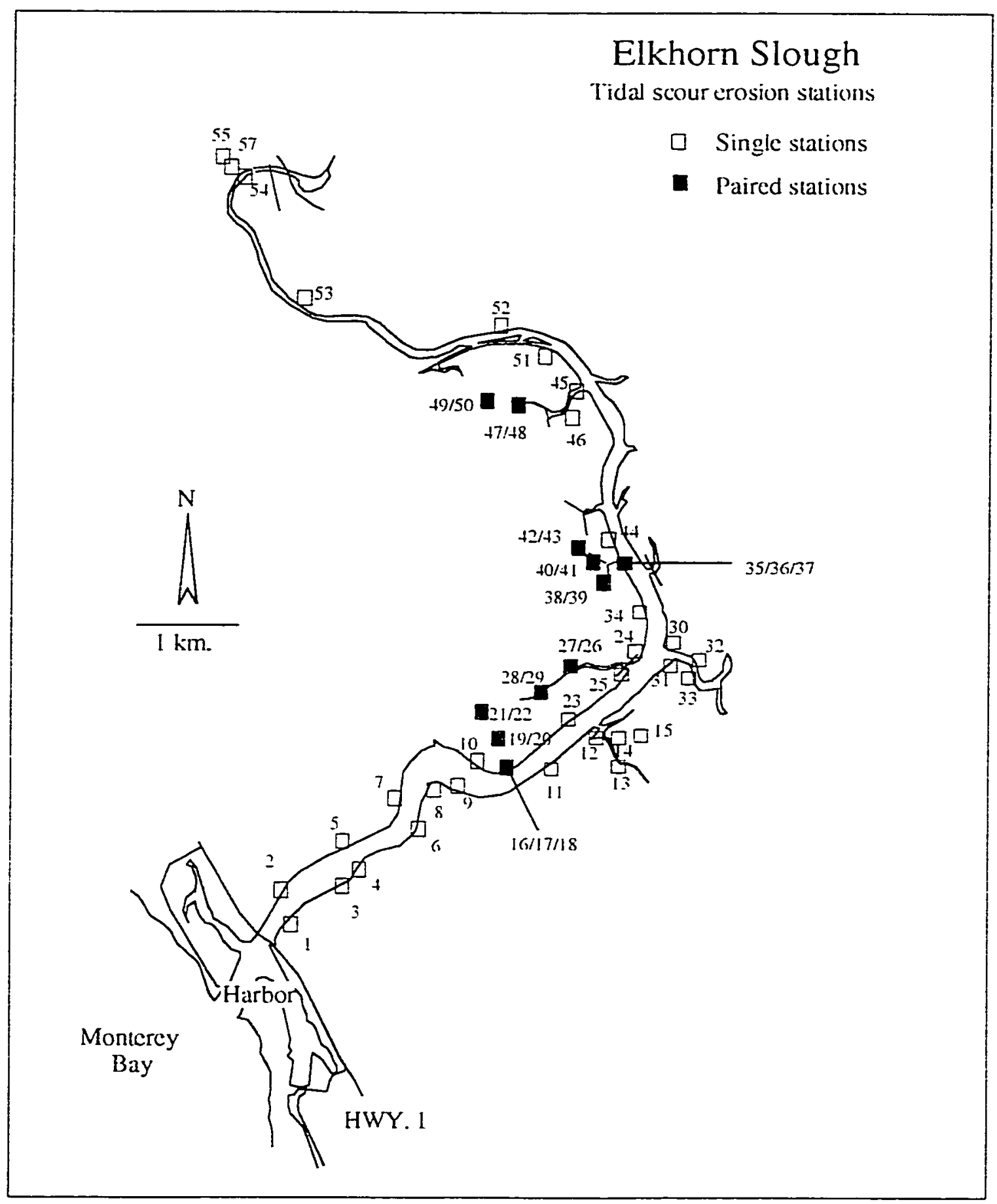

Figure 5. Elkhorn Slough showing location of tidal scour stations used to calculate bank erosion and saltmarsh erosion from April 1994 to April 1996. At each station a a permanent $10-\mathrm{m}$ transect. marked with two PVC stakes, was established $2 \mathrm{~m}$ away from the bank edge. Al paired stations. three PVC stakes were established from which two sets of measurements were made relative to transect lines (0 to $10 \mathrm{~m}$ and 10 to $20 \mathrm{~m}$ ). 
coefficient of transmissometer measurements to total suspended material (TSM)

concentration (S1-S6 in Fig. 4). Using SCUBA, 3.8-cm-diameter, 10-cm-long cores were collected in the main channei and mudflats. Cores in the lower intertidal zone were collected on the mudflat halfway between the marsh edge and the main channel. Saltmarsh sediments were sampled using the same procedure during ebb tide when the region was exposed subaerially. These sediments were sampled approximately $2 \mathrm{~m}$ away from the marsh edge to eliminate any bias due to redeposition of suspended sediment.

\section{Tidal Height Characteristics}

Tidal observations have not been made in Elkhorn Slough since the 1978 NOS survey. Consequently, Fischer and Porter tide gauges were installed at Kirby Park and the Highway One bridge (Fig. 1) in October 1993 to establish a recent tidal database and to provide a means to correct bathymetric data for tidal fluctuations. The stations were precisely leveled to National Geodetic Vertical Datum (NGVD) and then corrected to MLLW. At Kirby Park, tidal benchmarks $3651 \mathrm{~B}$ and $3651 \mathrm{C}$ set by National Ocean Service (NOS) in 1978 were releveled to benchmark ELK 2-I (1992). From these reference benchmarks, a laser theodolite was used to determine the elevation of the gauge relative to NGVD (Table 1).

To the west of the Highway One bridge, a gauge was mounted on a navigation piling in October 1993 following approval by the US Coast Guard (October 1993). Using California Department of Transportation (Cal Trans) benchmark BM 941 3623, set at the NW corner of the bridge, an elevation was determined by theodolite 
Table 1: Reference benchmarks and associated datum used for leveling of tide gauges.

Benchmark Stamping

BM 9413623

ELK 2-I

$3651 \mathrm{~B}$

$3651 \mathrm{C}$

\section{General Location Height above NGVD (m)}

Hwy. 1 Bridge

Kirby Rd.

Kirby Park

1.40

Kirby Park

1.30

measurements. Tide staffs were then installed at these stations and used to calibrate the mechanical tide gauges. These gauges recorded water level every 6 minutes onto a paper punch roll. Tapes were replaced and the gauges were cleaned twice a month.

\section{Water Volume}

There are 5 tributary basins that contribute to the total water volume of Elkhorn Slough: Salt Ponds, Dolan Marsh, South Marsh/ Parson's Slough, North Marsh, and Bloom/Porter Marsh (Fig. 1). To determine the variation in the water volume of each of these basins, field measurements of current flow and cross-sectional area were monitored at the entrance channels to these basins on 12 December 1993 (hydrological sampling stations on Fig. 4). The tidal variation on this date was from a high tide of $2.05 \mathrm{~m}$ to a low-tide of $-0.44 \mathrm{~m}$. Velocity measurements of water flow were made by inserting a handheld flow meter in the middle of the water column of each entrance channel. Flow 
was monitored for one minute, replicated 5 times, and then the 5 values were averaged to determine a mean velocity. This process was repeated hourly during ebb flow while depths of the channel cross-section were determined using a stadia rod. Continuous current velocity and pressure data were obtained at the Highway One bridge using an S4 current meter.

\section{Hydrology and Suspended Sediment Profiling}

Current velocities and transport of suspended sediment in an open channel have been shown to vary with water depth (Easterbrook, 1993). Three vertical profiling stations were established at the Highway One bridge where the channel bottom has depths of 2, 4 and $6.5 \mathrm{~m}$ below MLLW to determine if current velocity and sediment concentration variations exist at the entrance of Elkhorn Slough (Fig. 6). In December 1993 and February 1994, an InterOcean S4 current meter and a 5-cm SeaTech transmissometer measured current velocity and beam attenuation, respectively, during ebb flow, the time of greatest current speed and suspended sediment concentration. The instruments were suspended from a davit with the transmissometer situated I $\mathrm{m}$ above the current meter, which was $0.5 \mathrm{~m}$ above a $57-\mathrm{kg}$ weight. This array was lowered into the water column, stopping at $0.5 \mathrm{~m}$ intervals for one minute, to obtain readings. The S4 current meter measured vector-averaged current velocity, depth, salinity and temperature every 10 seconds. This averaging period allowed maximum efficiency based on the $128 \mathrm{~Kb}$ of memory in the $\mathrm{S} 4$ instrument. Output from the 


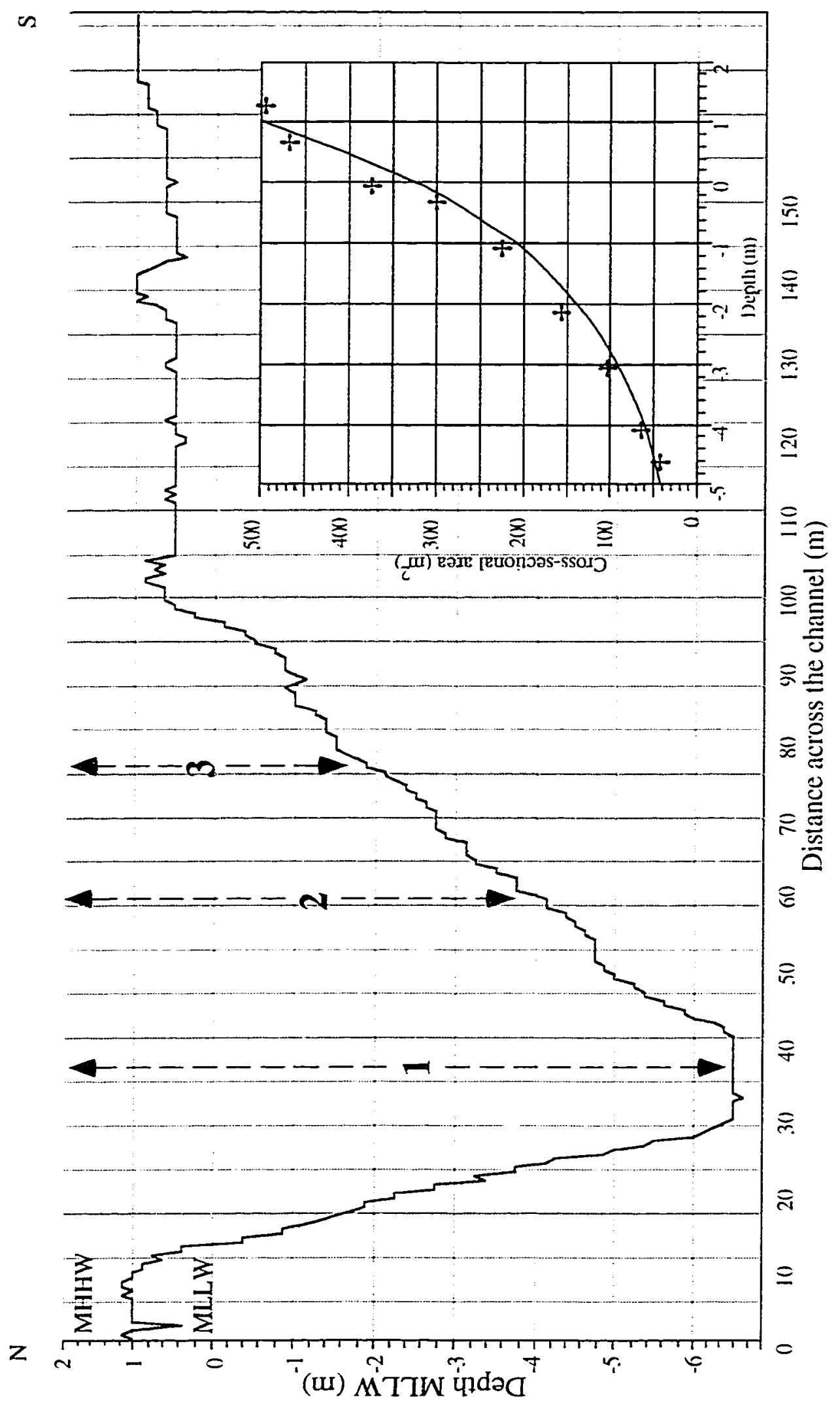

D্장 
transmissometer, expressed in volts, was recorded once a stable reading (minimal variance) was obtained at each depth. Following completion of the deepest measurement, the instruments were raised to the surface, transferred to the next station and redeployed in the same manner. A complete set of measurements was made at the 3 stations within one hour.

\section{Longterm Hydrologic and Suspended Sediment Monitoring}

Analysis of the current profiling data indicates that the average flow speed in the channel takes place at depth of $2.25 \mathrm{~m}$ below MLLW at Station 1 (Fig. 6). The S4 instrument and transmissometer were successfully deployed at this depth during the months of April, July and November 1994 for periods of 3 to 10 days. Measurements of vector-averaged current speed and depth were recorded every 5 minutes by the S4 instrument. The sampling frequency used in this deployment was sufficient to detect quarter diurnal characteristics in current velocity and sediment transport as well as the non-tidal Monterey Bay seiche that has a 25-minute period (Broenkow, 1996, personal communication). A Li-Cor data logger averaged beam attenuation, measured by the transmissometer, every 10 minutes.

To obtain reliable harmonic tidal constituents, a full month of tidal height and current velocity data were acquired by deploying three S4 current meters across the entrance channel of the slough during May 1996 (Fig. 6). For 29 tidal cycles, vectoraveraged current speed and depth were recorded every 10 minutes. 


\section{Bathymetry}

To produce a final map, raw UTM position data and depth data, obtained in November and December 1993, were reduced and corrected to MLLW using the tide gauge data. The resulting data set was contoured using the Delunay triangular averaging method and saved in a digital exchange format for transfer into a GIS database. The contours were then integrated with terrestrial maps and aerial photographs to produce the final bathymetric map.

To determine rates of lower-intertidal and subtidal erosion, cross-sections were produced at numerous locations for comparison to those documented by Oliver et al. (in review) (CS and SM transects in Fig. 4). Comparison of these data to previous analyses of Oliver et al. (in review) required a baseline for the 1988 data to be estimated because an accurate source for reference datum was not stated in the methods of Oliver et al. (in review). To produce this estimate, a graphical comparison of the 1988 and 1993 data was made by first vertically aligning the height of the Salicornia marsh at the bank edge in 1988 with the elevation of the same feature in 1993. The horizontal alignment was then adjusted by comparing the position of the channel axis in the 1988 cross-section to that of the 1993 cross-section. Once the 1988 and 1993 data were aligned, the accurately determined position of MLLW in the 1993 survey was transferred to the 1988 data.

The error for the datum adjustment described above is estimated to be no greater than one-half of the measured water depth at each of the measured transects based on the 
following rationale (CS \& SM series in Fig. 4). Salicomia is an intertidal plant species that requires periodic salt water irrigation for survival. In Elkhorn Slough, salt water irrigation of Salicornia takes place during tidal heights that fall between 0.95 and $2.35 \mathrm{~m}$ MLLW (person. comm. Tricia Lowe). At the bank edge (elevation $\sim 1.4$ to $2.0 \mathrm{~m}$ MLLW) a decrease in the elevation by $0.7 \mathrm{~m}$ would completely saturate the plant species with salt water and, subsequently, it would die off. Conversely, an increase in elevation by $0.7 \mathrm{~m}$ would place Salicornia in a supratidal environment. This situation would not only result in a lack of salt water irrigation and, hence, a demise in the population of the plant but would place it above the observed elevation range for Salicornia growth in Elkhorn Slough. At transect CS- $6, \mathrm{a} \pm 0.7 \mathrm{~m}$ change in elevation, as constrained by the datum provided by the Salicornia habitat, is approximately one-half of the maximum measured channel depth of the channel $(1.4 \mathrm{~m})$ at MLLW. All other transect locations are in regions where the channel is deeper, so the percent error at each location would be less. Therefore, the maximum error for the comparisons with the 1988 data of Oliver $e t$ al. (in review) are inferred to be no greater than $50 \%$ of the measured depth at each of the transects (CS \& SM series in Fig. 4).

Following this analysis, rates of lateral and vertical change in the subtidal and lower intertidal areas were determined by taking the average of 5 to 6 measurements along each transect. The slough was then divided into four areas based on distance from the slough mouth; lower slough ( 0 to $2500 \mathrm{~m}$ ), middle slough (2501 to $8600 \mathrm{~m}$ ), Parson's Slough (at $3600 \mathrm{~m}$ and extending to the Southern Pacific railroad trestle $50 \mathrm{~m}$ south), and the upper slough ( 8600 to $10,000 \mathrm{~m}$ ) (Oliver et al., in review; Malzone and Kvitek, 
1995). Volumetric estimates of sediment loss or gain were then determined through the trapezoidal integration of the product of cross-sectional area and length of the different levels of the 1988 and 1993 studies.

\section{Bank Erosion}

Rates of upper-intertidal erosion were quantified by analysis of bank retreat data. The data were categorized according to date, station and location (i.e. lower slough, middle slough, upper slough, Parson's Slough). Assuming a vertical slope of the bank down to the mudflat, rates of sediment loss in the upper intertidal area for a given region were determined by integrating the product of the average lateral retreat rate, the average vertical height of the banks and the length over a given time.

\section{Sedimentology}

Sediment core samples were collected in the slough to quantify sediment properties in the three different tidal environments subject to scour, the subtidal, lower intertidal and the upper intertidal. Excess water was removed from the top of each sample core and the upper $4 \mathrm{~cm}$ of sediment was extruded. Samples were weighed, dried and reweighed to determine wet and dry densities of the sediment. Porosities for each sample were then calculated using a water density of $1.0 \mathrm{~g} / \mathrm{cm}^{3}$. Sedimentology data were categorized into 3 groups of two transects based on location in the slough (i.e.: S1 and S2 = lower slough, S3 and S4 = middle slough, and S5 and S6 = upper slough). The remainder of each core was archived for later analysis of grain size and effect upon light 
beam attentuation as suspended sediment. Light beam attenuation values were used for calibration of the transmissometer measurements.

\section{Tidal Height Characteristics}

Tidal relations were analyzed on $15 \mathrm{~S} 4$ instrument sampling days and 5 bathymetric survey days. Water level records were stored in reference to the National Geodetic Vertical Datum (NGVD) and corrected to Mean Lower Low Water (MLLW). For the Monterey Bay, the correction is $+0.81 \mathrm{~m}$ from NGVD to MLLW. Tidal height values for the stations at Kirby Park and Highway One were plotted to examine differences in tidal height, tidal range and phase lag between the two locations.

To obtain all major tidal constituents for the Elkhorn Slough, data were acquired for a full month during May 1995. During the month-long deployment in May 1995, pressure (depth) information was obtained from the S4 instrument. These measurements were corrected to MLLW by determining the position of the instrument relative to benchmark BM 9413623 and then analyzed using a least squares harmonic regression technique. The harmonic regression uses a trigonometric series expressed as:

$$
\mathrm{H}=\mathrm{H}_{\mathrm{O}}+\sum \mathrm{A}_{\mathrm{i}}\left[\cos \left(\mathrm{N}_{\mathrm{i}}^{*} \mathrm{t}-\mathrm{L}_{\mathrm{i}}\right)\right]
$$

where $H$ is the tidal height, $H_{0}$ is the MLLW level, $A_{i}$ is the amplitude of the $i-$ th constituent, $N_{i}$ is the speed number (deg/hr) of that constituent, $t$ is the time from the beginning of the deployment, and $\mathrm{L}_{\mathrm{i}}$ is the phase lag of the $\mathrm{i}$-th constituent relative to the start of the series (Wong, 1989). The tidal character of the slough is described by the 
constituents that are used to calculate the principal tidal range $(\mathrm{K} 1+\mathrm{O} 1+\mathrm{M} 2+\mathrm{S} 2)$ and the quarter diurnal tidal period, M4 (Wong, 1989).

\section{Water Volume}

The water volume exchange during tidal cycles for each of the 5 tributary basins on 12 December 1993 was determined by taking the product of the average water flow, the cross-sectional area and ebb flow duration at each basin entrance. From this calculation, the change in water volume from a $2.06 \mathrm{~m}$ to a $-0.44 \mathrm{~m}$ tidal height was analyzed and corrected to the MLLW datum. Bathymetry data and aerial photographs were used to determine the volume of the tributary basins, the Elkhorn Slough main channel and adjacent mudflats and marsh at MLLW, a reference datum for other data collected as part of this study. All data were integrated and compared to the cumulative water volume as determined from current meter data at the Highway One bridge, and previous estimates by Smith (1973), Broenkow (in review) and Wong (1989). Aerial photographs from 1980, 1988 and 1992 were then used to quantify annual changes in the wetted area for each location monitored and the cumulative wetted area for Elkhorn Slough.

\section{Hydrology and Suspended Sediment Profiles}

During the profiling of current speed and suspended sediment concentration, the S4 instrument obtained pressure (decibars) and current velocity $(\mathrm{cm} / \mathrm{s})$ data while a LiCor data logger recorded values of light beam transmittance (volts) from the 
transmissometer. A beam of light passing through water is attenuated by the independent processes of scattering and absorption. Scattering is the process in which a light beam is deflected from its original direction (Austin and Petzold, 1975). Attenuation, mainly through scattering, has been found to have a direct correlation to the amount of particulate matter (i.e. suspended sediment), however, the magnitude of scattering is dependent on the size, shape and refractive index of the particles and the medium in which the particles are suspended (Austin and Petzold, 1975). The total light attenuation, due to the combined effects of scattering and absorption, determines the beam transmission property of water. The equation governing the relationship between light beam attenuation and transmittance is expressed as:

$$
\mathrm{T}=\mathrm{I} \mathrm{L}_{\mathrm{o}}=\mathrm{e}^{-\mathrm{cL}}
$$

where $c$ is the attenuation coefficient, $T$ is transmittance and $L$ is the pathlength, $I_{0}$ is the intensity of the unattenuated light beam and $I$ is the beam intensity emerging from path $L$. Due to high concentrations of suspended sediment in the waters of the slough, a transmissometer with a $5-\mathrm{cm}$ pathlength was chosen (Fig. 7). The beam attenuation coefficient is obtained from measured values of $\mathrm{T}$ as:

$$
c=-\ln (\mathrm{T}) / \mathrm{L}(3)
$$

To determine the precise relation between suspended sediment concentration and light attenuation, Elkhom Slough sediment samples were introduced in aliquots to a 10gallon container filled with seawater. To insure proper suspension, the bucket was stirred after each aliquot. Once stirred, light attenuation was measured by the transmissometer 


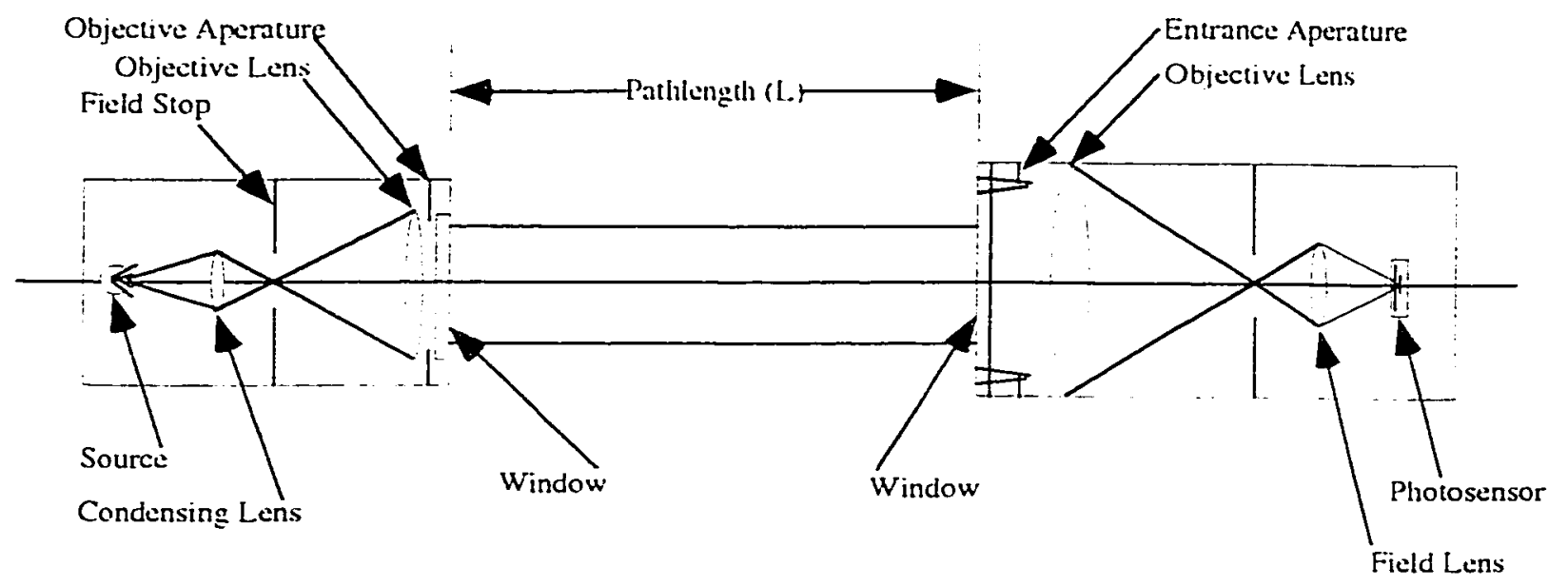

Figure 7. Schematic drawing of a transmissometer collimated optical system similar to the one used during this study (Austin and Petzold. 1975). 
while a water sample was collected. Suspended sediment concentration was increased with additional sediment and stirring until 8 separate readings were obtained. Water samples collected in Elkhorn Slough and in the laboratory were filtered, weighed, and compared to values obtained by the transmissometer (Fig. 8). Following this analysis, the following relation was established:

$$
\mathrm{TSM}=6.23+2.94 \mathrm{c}(4)
$$

where $\mathrm{c}$ is the attenuation coefficient and TSM is the total suspended material with an intercept of 6.23 , correlating with the lowest concentration of TSM found in seawater as detected by this transmissometer and by laboratory analysis of water samples collected offshore of Moss Landing (person. comm. Dr. W.W. Broenkow). Once this empirical relationship was established, values for current speed, suspended sediment concentration and depth were plotted and variations with depth were determined.

\section{Longterm Monitoring}

Advective sediment fluxes in Elkhom Slough were calculated using the flow component that is perpendicular to the main channel cross-section. Tidal currents can be resolved into two local vectors based on the direction of the flood current. During monitoring, current direction and velocity were recorded by the S4 instrument. The direction of flow in Elkhorn Slough is confined by the channel orientation, which is determined from bathymetry studies to be to the southwest or $225^{\circ}$ magnetic. Following calculations by Reilly (1978) and Wong (1989), the vector components for average tidal flow in Elkhorn Slough are $U$, representing the along channel direction (in the direction 


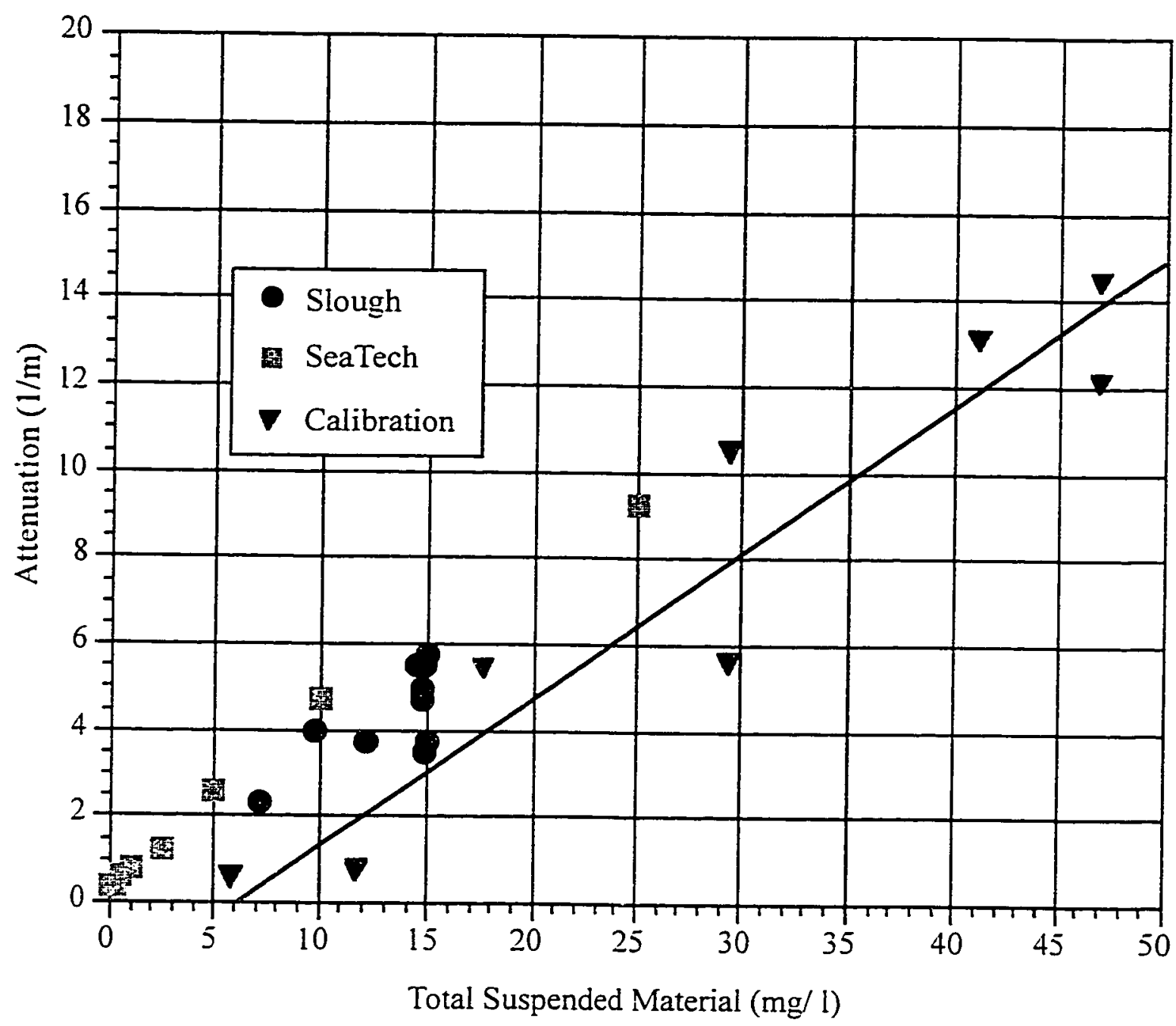

Figure 8. Graphs of Attenuation (c) versus TSM used in calibration of the transmissometer. "Slough" numbers represent water samples collected during the longterm monitoring. "SeaTech" numbers represent calibration values provided by the manufacturer. "Calibration" numbers represent values obtained during laboratory calibration of the transmissometer through mixing of Elkhorn Slough sediments and seawater in a 10-gallon container. The linear regression of the "Calibration" values yields: $\mathrm{TSM}=6.23+2.94 \mathrm{c}$. 
of flooding), and V, representing the cross-channel direction (positive to the southeast). The equations governing these relationships are:

$$
\begin{aligned}
& U=s[\cos (D-45)] \\
& V=s[\sin (D-45)]
\end{aligned}
$$

where s represents current speed, and D is the magnetic direction of the current in degrees, and 45 is the orientation of the channel in the flooding direction. The $U$ or along-channel velocities were further analyzed by harmonic regression using the same method as outlined in "Tidal Height" but substituting $\mathrm{U}$ for $\mathrm{H}$ in equation 1 (see page 23).

For the calculation of suspended sediment flux, $U$ is expressed in $\mathrm{m} / \mathrm{s}$, sediment concentration $(\mathrm{S})$ in $\mathrm{kg} / \mathrm{m}^{3}$, and tidal height $(\mathrm{H})$ is given in $\mathrm{m}$. Cross-sectional area, $\mathrm{A}$ $\left(\mathrm{m}^{2}\right)$, is determined by integration of the channel depths at different tidal heights to give the relation:

$$
A=320 e^{0.43 z}(7)
$$

where $z$ is the depth relative to MLLW (Fig. 6). The instantaneous sediment transport $(\mathrm{kg} / \mathrm{s})$ is the product of $\mathrm{U} \times \mathrm{S} \times \mathrm{A}$, whereas the net suspended sediment transport (T) for a given period (dt) is the integration of $U \times \mathrm{S} \times$ A over the sampling time:

$$
\mathrm{T}_{\text {sed }}=\int \mathrm{USA} \mathrm{dt}
$$

A similar operation can be performed for water transport:

$$
\mathrm{T}_{\text {water }}=\int \mathrm{UAdt}
$$

This operation determines the overall water budget for Elkhorn Slough (Reilly, 1978). 
RESULTS

\section{Bathymetry}

Bathymetry data show a meandering main channel in Elkhorn Slough that decreases from a depth of $6.5 \mathrm{~m}$ and width of $150 \mathrm{~m}$ near the mouth to a depth of $1.7 \mathrm{~m}$ and width of $25 \mathrm{~m}$ at Hudson's Landing (Plate 1). The greatest water depths occur at bends of the channel (e.g., Seal Bend) while shoaling tends to take place near the midpoints of straight sections in the channel (e.g., between the Highway One bridge and Seal Bend) (Fig. 9). In the middle slough region, shoaling is produced by the formation of depositional mud-bars while in the lower slough the formation of Zostera marina seagrass beds appears to be a controlling mechanism.

Comparisons of the 1993 bathymetric study presented here and the 1988 results of Oliver and others (in review) depend on the selection of a reference datum. Previously, it was shown that errors in the reference datum do not exceed $50 \%$ (see discussion on page 21). The calculated rates of sediment loss are very large and still significant for predictions of morphological change to Elkhorn Slough.

The comparisons from 1988 (Oliver et al., in review) to 1993 (this study) show channel widening throughout the slough while scouring and deepening have been restricted to the upper slough (Fig. 10, Table 2). Listed on Table 2 are the minimum and maximum measured values for lateral and vertical change at each transect between 1988 and 1993 as well as the average subtidal and intertidal erosion rates (lateral and vertical) for this period. 


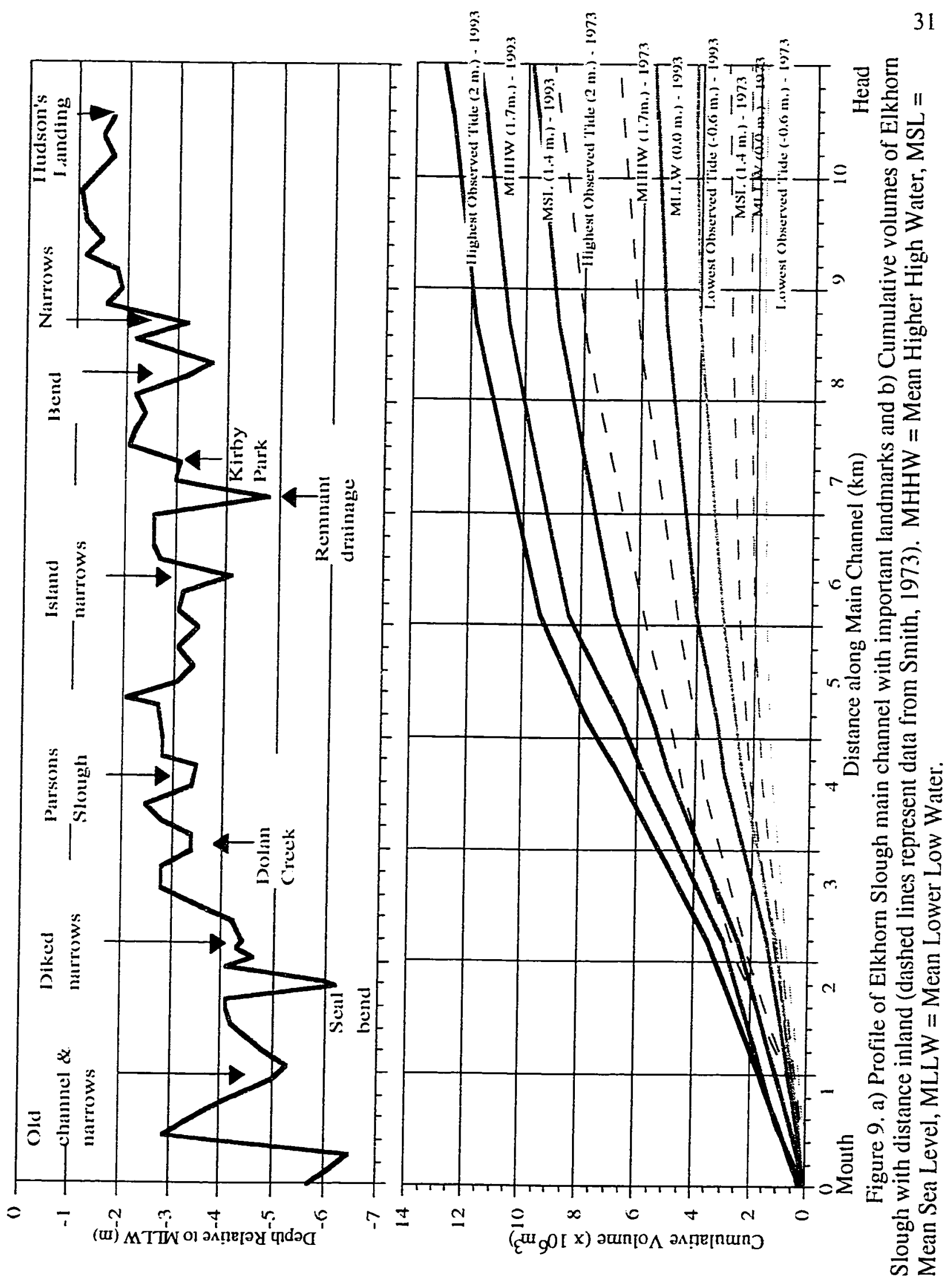




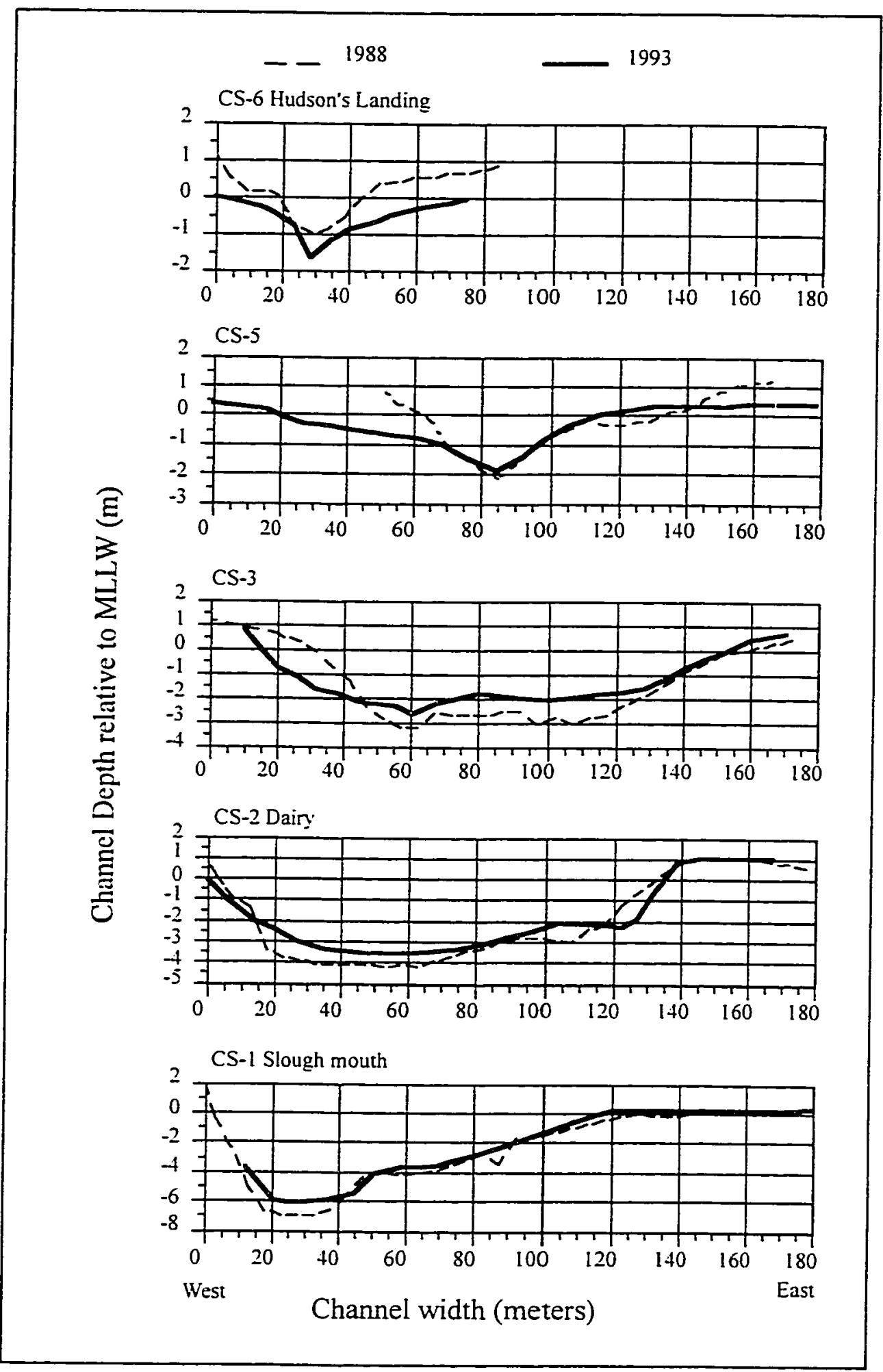

Figure 10. Comparison of 1988 (Oliver et al.) and 1993 main channel depth profiles at five locations along the length of the Elkhorn Slough. Cross-section transect locations are shown in Figure 4 (Note: variation in vertical scales). 
Table 2. Subtidal and lower-intertidal erosion rates based on changes from 1988 (Oliver et al., in review) and 1993 cross-sectional data. " + " = deposition and "-" = erosion. LIT = lower intertidal and ST = subtidal (nd = no data). The calculation of average rates is described on page 21 .

Transect Position Lateral Change (m) Vertical Change (m) Avg. Rates (m/yr)

Number $\min \max$ $\min \max$

Lateral Vertical

$\begin{array}{llllllll}\text { CS-1 } & \text { LIT } & -2.0 & -4.0 & -0.9 & -1.1 & -0.63 & -0.17 \\ \text { CS-1 } & \text { ST } & +6.0 & -2.0 & +1.0 & +1.5 & +0.81 & +0.27 \\ \text { CS-2 } & \text { LIT } & -3.0 & -5.0 & -0.8 & -1.2 & -0.81 & -0.27 \\ \text { CS-2 } & \text { ST } & -3.0 & -9.0 & +0.5 & +1.2 & -1.62 & +0.18 \\ \text { CS-3 } & \text { LIT } & -10.0 & -15.0 & +1.0 & -0.5 & -2.52 & +0.04 \\ \text { CS-3 } & \text { ST } & -7.0 & -14.0 & +0.9 & -1.6 & -1.98 & -0.18 \\ \text { CS-4 } & \text { LIT } & -12.0 & -28.0 & +0.2 & -0.6 & -3.96 & +0.04 \\ \text { CS-4 } & \text { ST } & -23.0 & -35.0 & +0.2 & -0.1 & -5.76 & -0.18 \\ \text { CS-5 } & \text { LIT } & -54.0 & -68.0 & -0.8 & -1.2 & -12.15 & -0.18 \\ \text { CS-5 } & \text { ST } & -43.0 & -68.0 & +0.3 & -1.1 & -10.98 & -0.18 \\ \text { CS-6 } & \text { LIT } & -28.0 & -33.0 & -0.5 & -0.8 & -6.12 & -0.09 \\ \text { CS-6 } & \text { ST } & -34.0 & -37.0 & -0.8 & -1.2 & -7.11 & -0.18 \\ \text { SM-1 } & \text { LIT } & -40.0 & -85.0 & -1.0 & -1.5 & -12.42 & -0.27 \\ \text { SM-1 } & \text { ST } & -5.0 & -40.0 & -0.5 & -1.5 & -4.50 & -0.18 \\ \text { SM-2 } & \text { LIT } & -9.0 & -15.0 & -1.0 & -1.2 & -2.43 & -0.18 \\ \text { SM-2 } & \text { ST } & -8.0 & -12.0 & -0.5 & -2.0 & -1.98 & -0.27 \\ \text { SM-3 } & \text { LIT } & -8.0 & -12.0 & n d & n d & -1.98 & \text { nd } \\ \text { SM-3 } & \text { ST } & -4.0 & -8.0 & -0.5 & -2.0 & -1.53 & -0.27\end{array}$


At the mouth of the slough (transect CS-1), calculations (from 1988 to 1993) indicate a range of 2 to $4 \mathrm{~m}$ of lateral migration of the north bank (average rate of 0.6 $\mathrm{m} / \mathrm{yr}$ ), $1 \mathrm{~m}$ of vertical loss of material from the mudflats on the south side of the slough and a $0.27 \mathrm{~m} / \mathrm{yr}$ deposition rate in the main channel (Fig. 10, Table 2). At middle slough transects CS-3 \& CS -4 , widening of the channel ranged from 7 to $35 \mathrm{~m}$ with an average vertical scour rate of $0.18 \mathrm{~m} / \mathrm{yr}$ in the subtidal region and a $0.04 \mathrm{~m} / \mathrm{yr}$ average deposition rate in the lower intertidal area. The largest changes are located at CS-5 and CS- 6 in the upper-slough region east of Kirby Park with a maximum loss of $1 \mathrm{~m}$ vertically and $68 \mathrm{~m}$ laterally. Average vertical scour rates were calculated to be up to $0.18 \mathrm{~m} / \mathrm{yr}$ in the lower intertidal zone and $0.18 \mathrm{~m} / \mathrm{yr}$ in the subtidal zone.

Changes in cross-sectional area were also observed at the entrance channel to Parson's Slough (Fig. 11, Table 2). Transects SM-1, SM-2 and SM-3 have increased in width by 85,15 and $12 \mathrm{~m}$, respectively. The depth increases at transects SM-1, SM-2 and SM-3 between 1988 and 1993 are $1.5,2.0$ and $2.0 \mathrm{~m}$, respectively. Average rates of channel bed loss due to erosion in this region were calculated at $0.23 \mathrm{~m} / \mathrm{yr}$ in the lowerintertidal and $0.24 \mathrm{~m} / \mathrm{yr}$ in the subtidal nain channel.

\section{Bank Erosion}

Aerial photographic and bank erosion measurements confirm the differential pattern of erosion in the slough with rates remaining high and, in some places, increasing since 1988 (Oliver et al., in review). The highest rates of bank migration and, therefore, 


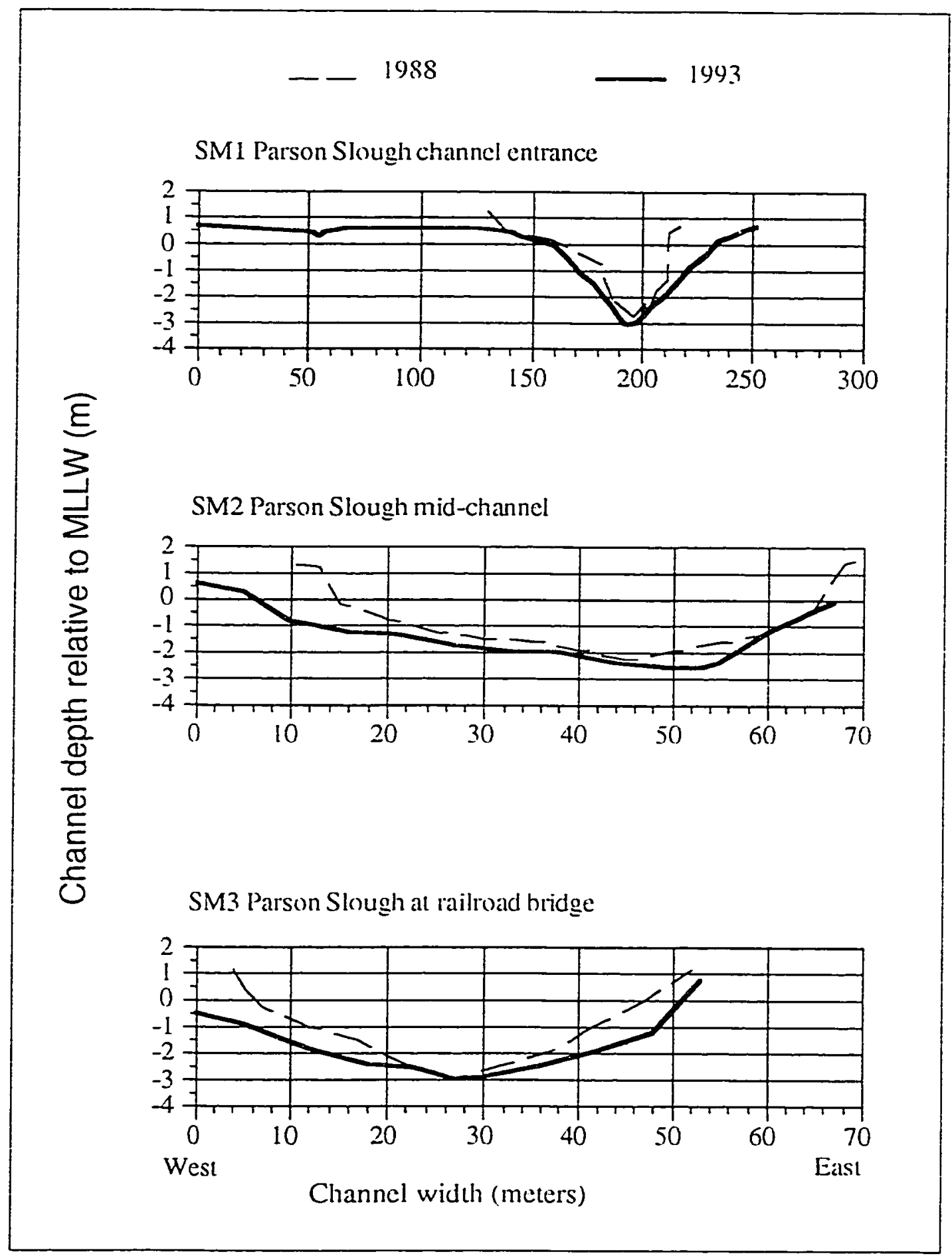

Figure 11. Comparison of 1988 (Oliver et al.) and 1993 channel depth profiles at three locations near the entrance of Parsun's Slough. Cross-section transect locations are shown in Figure 4 (Note: Variation in horizontal scales). 
erosion are in the vicinity of the entrance channel to the Parson's Slough (SM-1), the tidal creeks and within the upper slough (CS-5 and CS-6). Channel width increases in the Parson's Slough, tidal creeks and upper slough have rates exceeding $0.4 \mathrm{~m} / \mathrm{yr}, 0.1 \mathrm{~m} / \mathrm{yr}$ and $0.5 \mathrm{~m} / \mathrm{yr}$, respectively, from 1994 to 1996 (Fig. 12, Table 3). Table 3 lists bank erosion rates and the average distance from the erosion stakes to the bank edge for each of the years sampled. All data are categorized by station number and region (e.g., lower slough).

\section{Sedimentology}

Sediments in Elkhom Slough are composed of organic-rich muds laden with plant material in the upper-intertidal area, a mixture of organic-rich muds with plant material and inorganic muds and clays in the lower-intertidal region, and mostly inorganic muds and clays in the subtidal area. Analyses of sediment densities and porosities show a great deal of variation between the six transects (Fig. 13). At transect S2, located in the lower slough near Seal Bend (Fig. 4), sediment samples from the main channel exhibit slightly greater densities and lower porosities than sediment within the main channel along transect S1 (Highway One bridge). This situation results from a 1-cm-thick layer of very coarse, poorly sorted shell debris in the main channel along transect S1. Sediments below this layer may, however, reflect patterns similar to those at transect $\mathbf{S}$.

Main channel sediments become less dense and more porous inland (transects S3S6). Wet and dry sediment densities in the tidal flat regions show little variation between 


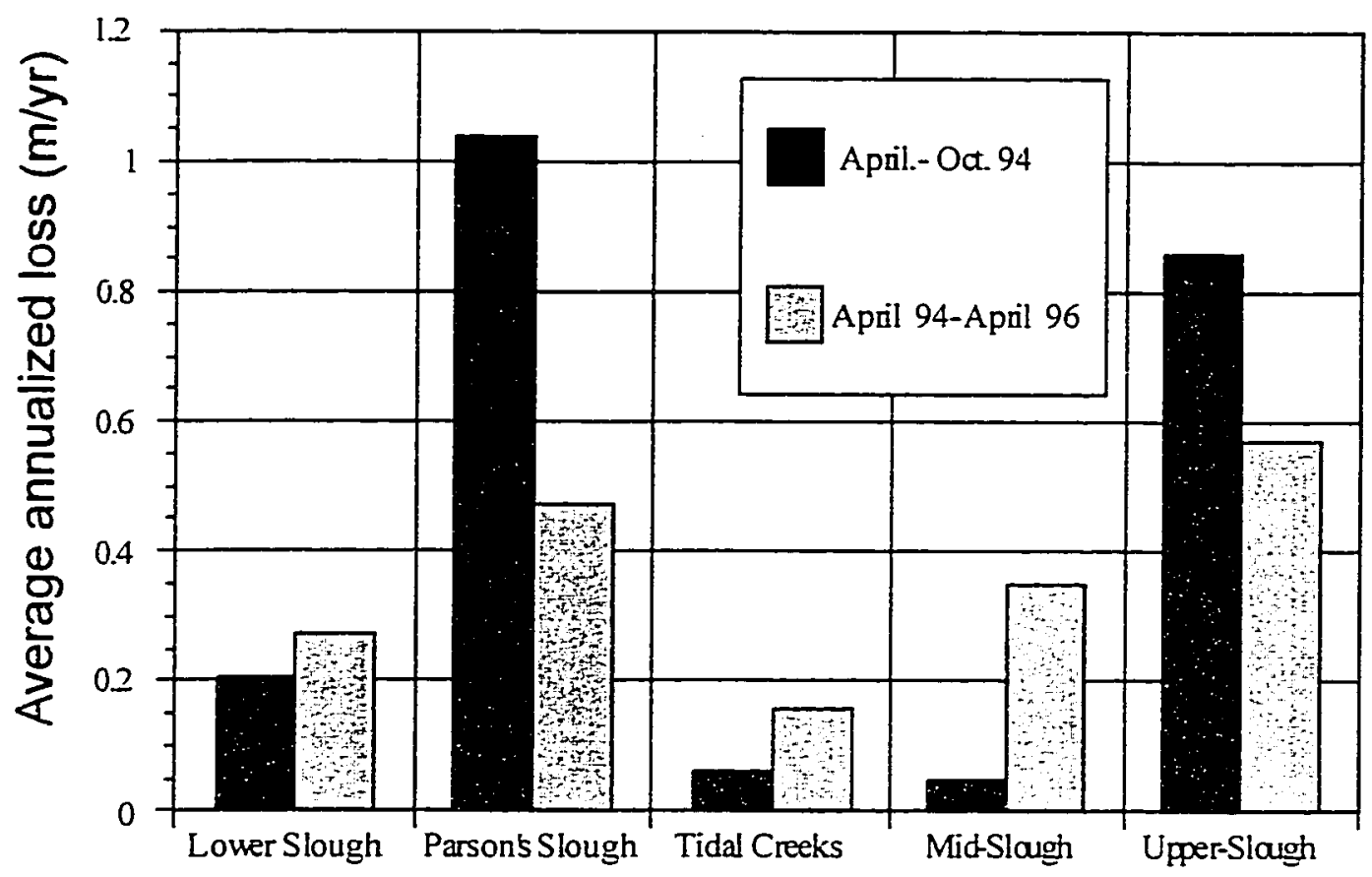

Figure 12. Annualized lateral loss of marsh bank from the shorelines of Elkhorn Slough. Based on values obtained during bank erosion measurements (at stations shown in Fig. 5) during April to October 1994 and April 1994 to April 1996. 
Table 3. Bank migration measurements for Elkhorn Slough from April 1994 to April 1996 based on station number (Fig. 5) and region. Negative numbers indicate erosion while positive numbers indicate deposition.

\begin{tabular}{|c|c|c|c|c|c|}
\hline \multirow[b]{2}{*}{ Station \# } & \multirow[b]{2}{*}{ Region } & \multicolumn{2}{|c|}{ Distance to Bank Edge } & \multicolumn{2}{|c|}{ Change Rate } \\
\hline & & April 1994 & April 1996 & $(\mathrm{~m})$ & $(\mathrm{m} / \mathrm{yr})$ \\
\hline 2 & Lower Slough & 1.89 & 1.02 & -0.87 & -0.44 \\
\hline 3 & Lower Slough & 1.96 & 1.32 & -0.64 & -0.32 \\
\hline 5 & Lower Slough & 2.25 & 1.81 & -0.44 & -0.22 \\
\hline 6 & Lower Slough & 2.33 & 2.03 & -0.30 & -0.15 \\
\hline 7 & Lower Slough & 1.88 & 1.52 & -0.36 & -0.18 \\
\hline 8 & Lower Slough & 2.17 & 1.86 & -0.31 & -0.16 \\
\hline 9 & Lower Slough & 2.18 & 1.67 & -0.51 & -0.26 \\
\hline 10 & Lower Slough & 2.19 & 1.21 & -0.98 & -0.49 \\
\hline 11 & Middle Slough & 1.28 & 0.38 & -0.90 & -0.45 \\
\hline 12 & Tidal Creek & 2.15 & 1.79 & -0.36 & -0.18 \\
\hline 13 & Tidal Creek & 1.93 & 0.00 & -1.93 & -0.97 \\
\hline 14 & Tidal Creek & 1.89 & 1.68 & -0.21 & -0.11 \\
\hline 15 & Tidal Creek & 1.54 & 1.71 & 0.17 & 0.09 \\
\hline 16 & Middle Slough & 2.05 & 0.00 & -2.05 & -1.03 \\
\hline 23 & Middle Slough & 1.98 & 1.98 & 0.00 & 0.00 \\
\hline 24 & Middle Slough & 2.48 & 2.16 & -0.32 & -0.16 \\
\hline 25 & Middle Slough & 2.09 & 1.86 & -0.23 & -0.12 \\
\hline 26 & Middle Slough & 2.16 & 2.00 & -0.16 & -0.08 \\
\hline 27 & Middle Slough & 2.03 & 2.06 & 0.03 & 0.02 \\
\hline 28 & Middle Slough & 2.28 & 2.16 & -0.12 & -0.06 \\
\hline 29 & Parson's Slough & 2.23 & 1.92 & -0.31 & -0.16 \\
\hline 30 & Parson's Slough & 1.74 & 1.04 & -0.70 & -0.35 \\
\hline
\end{tabular}


Table 3, continued.

\begin{tabular}{|c|c|c|c|c|c|}
\hline \multirow[b]{2}{*}{ Station \# } & \multirow[b]{2}{*}{ Region } & \multicolumn{2}{|c|}{ Distance to Bank Edge } & \multicolumn{2}{|c|}{ Change Rate } \\
\hline & & April 1994 & April 1996 & $(\mathrm{~m})$ & $(\mathrm{m} / \mathrm{yr})$ \\
\hline 31 & Parson's Slough & 2.20 & 1.99 & -0.21 & -0.11 \\
\hline 32 & Parson's Slough & 2.18 & 1.11 & -1.07 & -0.54 \\
\hline 33 & Parson's Slough & 1.96 & 0.17 & -1.79 & -0.90 \\
\hline 34 & Middle Slough & 1.67 & 1.56 & -0.11 & -0.06 \\
\hline 35 & Middle Slough & 2.25 & 1.45 & -0.80 & -0.40 \\
\hline 36 & Middle Slough & 1.84 & 1.61 & -0.23 & -0.12 \\
\hline 37 & Middle Slough & 2.24 & 1.33 & -0.91 & -0.46 \\
\hline 38 & Tidal Creek & 1.93 & 1.91 & -0.02 & -0.01 \\
\hline 39 & Tidal Creek & 1.96 & 1.84 & -0.12 & -0.06 \\
\hline 40 & Tidal Creek & 2.04 & 1.80 & -0.24 & -0.12 \\
\hline 41 & Tidal Creek & 2.08 & 2.07 & -0.01 & -0.01 \\
\hline 44 & Tidal Creek & 1.92 & 1.40 & -0.52 & -0.26 \\
\hline 45 & Tidal Creek & 1.94 & 1.73 & -0.21 & -0.11 \\
\hline 46 & Tidal Creek & 2.07 & 1.94 & -0.13 & -0.07 \\
\hline 47 & Tidal Creek & 2.15 & 1.97 & -0.18 & -0.09 \\
\hline 48 & Tidal Creek & 1.81 & 1.56 & -0.25 & -0.13 \\
\hline 51 & Upper Slough & 2.04 & 0.54 & -1.50 & -0.75 \\
\hline 52 & Upper Slough & 2.26 & 2.07 & -0.19 & -0.10 \\
\hline 53 & Upper Slough & 1.93 & 0.43 & -1.50 & -0.75 \\
\hline
\end{tabular}



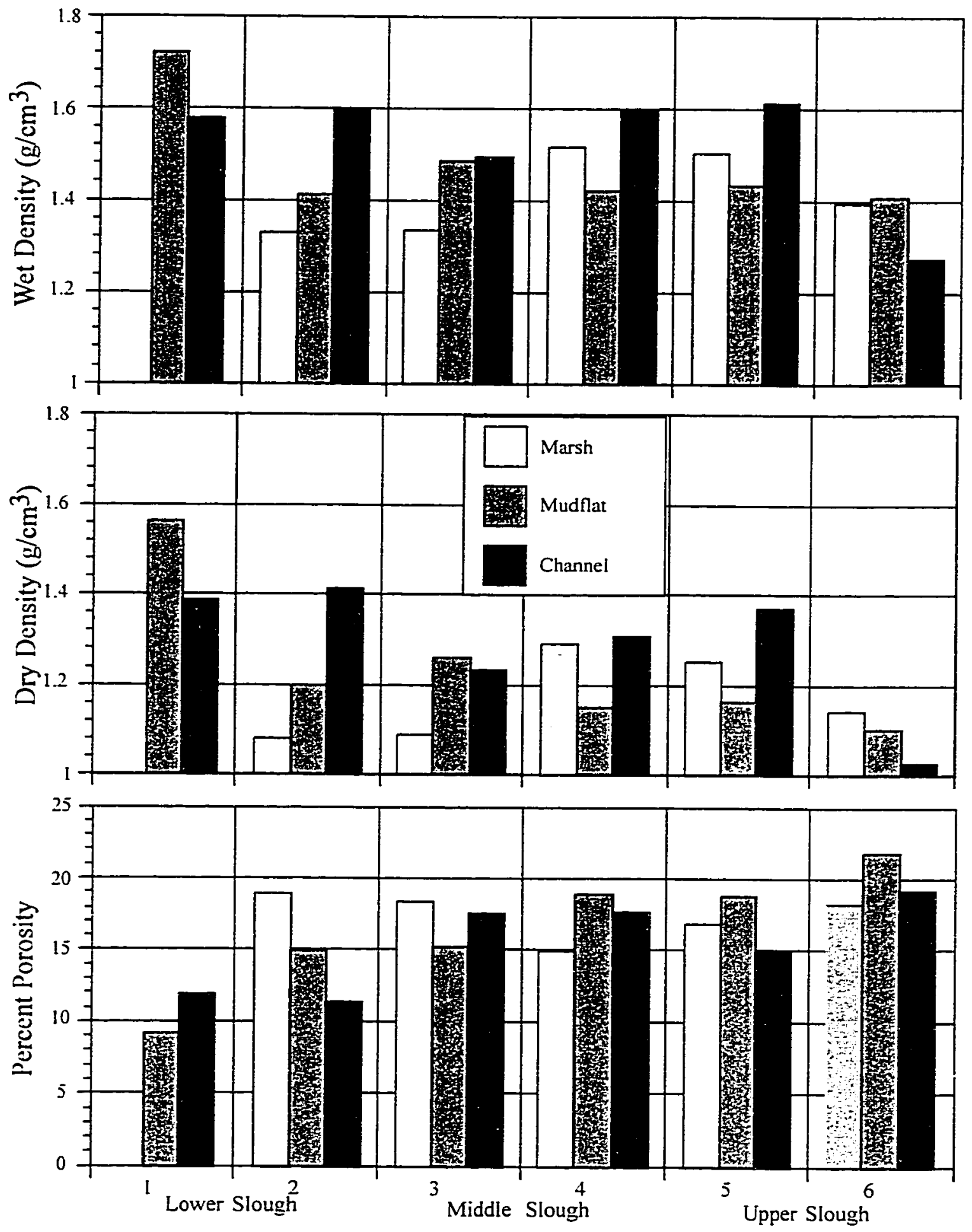

Transect Number

Figure 13. Sediment analysis results showing wet and dry densities as well as porosities for marsh, mudflat, and channel sediments taken at the transects ( $\mathrm{S}$ series) shown in Figure 4. 
transects S2 and S6; dry sediment densities range from 1.12 to $1.25 \mathrm{~g} / \mathrm{cm}^{3}$. The higher density and lower porosity in the lower slough tidal flat $\left(1.56 \mathrm{~g} / \mathrm{cm}^{3}\right.$ and $9.0 \%$, respectively) at transect S1 result from the very fine-grained, well-sorted sand at this site, in contrast to the muddy composition of the samples collected in the tidal flats of the middle and upper slough.

\section{Tidal Height Characteristics}

Tide gauge data show slightly greater tidal heights (average of $2 \mathrm{~cm}$ ) at Kirby Park than at the slough mouth, with an average phase lag of 17 minutes between the two stations (Fig. 14). The harmonic constituents derived from the regression of the Highway One S4 current meter data in May 1995 (Fig. 15) show that the tide is mixed semi-diurnal with a principal range $(\mathrm{K} 1+\mathrm{O} 1+\mathrm{M} 2+\mathrm{N} 2)$ of $1.16 \mathrm{~m}$ and a mean tidal height of $1.06 \mathrm{~m}$ MLLW. Tidal periods in Elkhom Slough are asymmetric with ebb tide averaging 0.5 to 1 hour shorter than the flood tide. All tidal height results are comparable to those of the 1978 NOS survey.

\section{Hydrology}

Tidal currents in Elkhorn Slough are standing wave in character with maximum velocities taking place near half tide, while slack water is found to take place at high and low tide (Fig. 16). Tidal current periodicity is asymmetric with 6 to 8 hours for flooding and 4 to 6 hours for ebbing. This asymmetry results in water slowly reentering the slough at the completion of the ebb but quickly exiting at the completion of flood. 


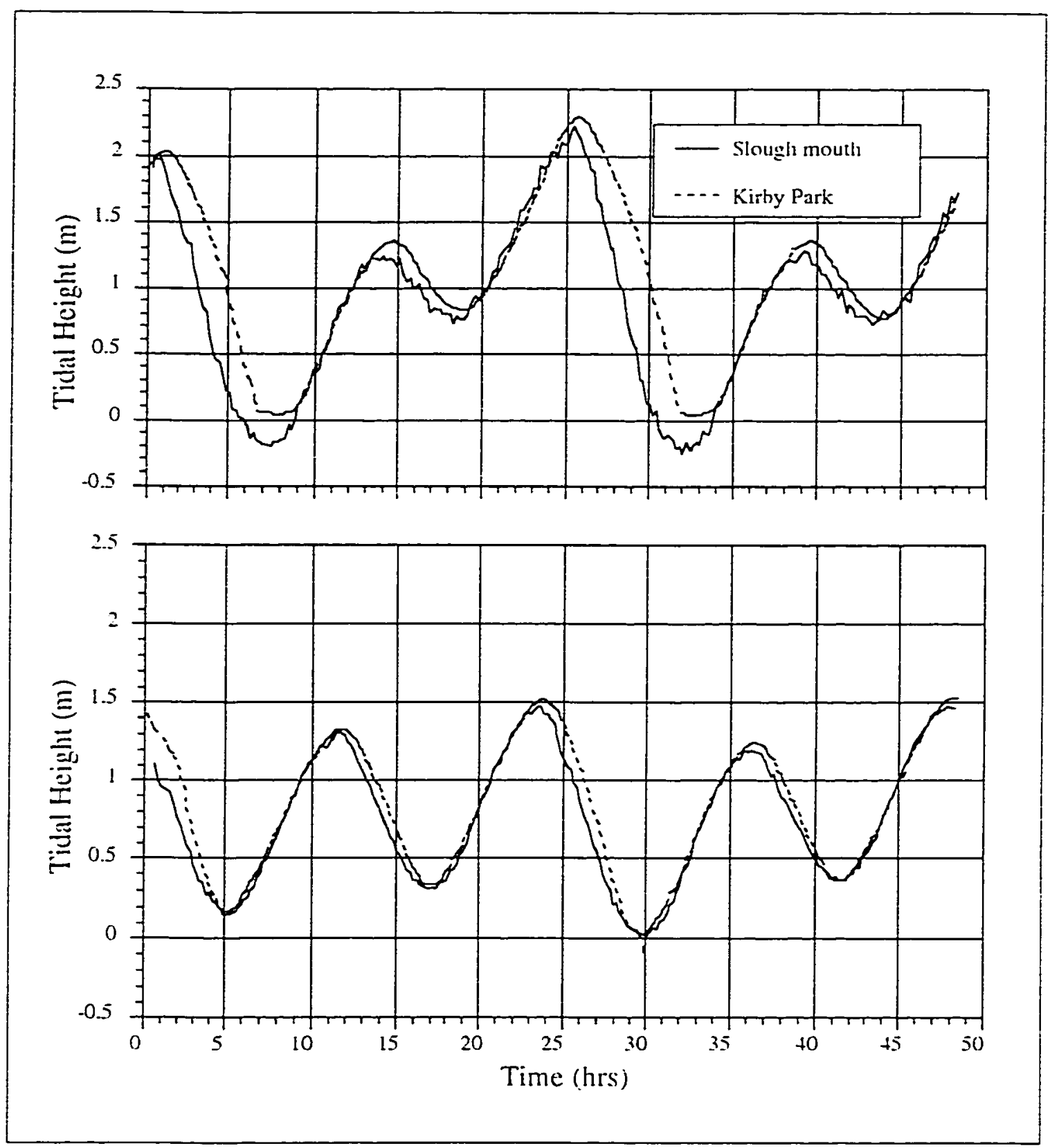

Figure 14. Top: Spring tidal regime in Elkhorn Slough (0430 hrs., 10 December to 0500 hrs..12 December 1994). Bottom: Neap tidal regime (1200 hrs.. 9 April to 1200 hrs.. 11 April 1994). Data collected from Fisher and Porter tide gauges. 


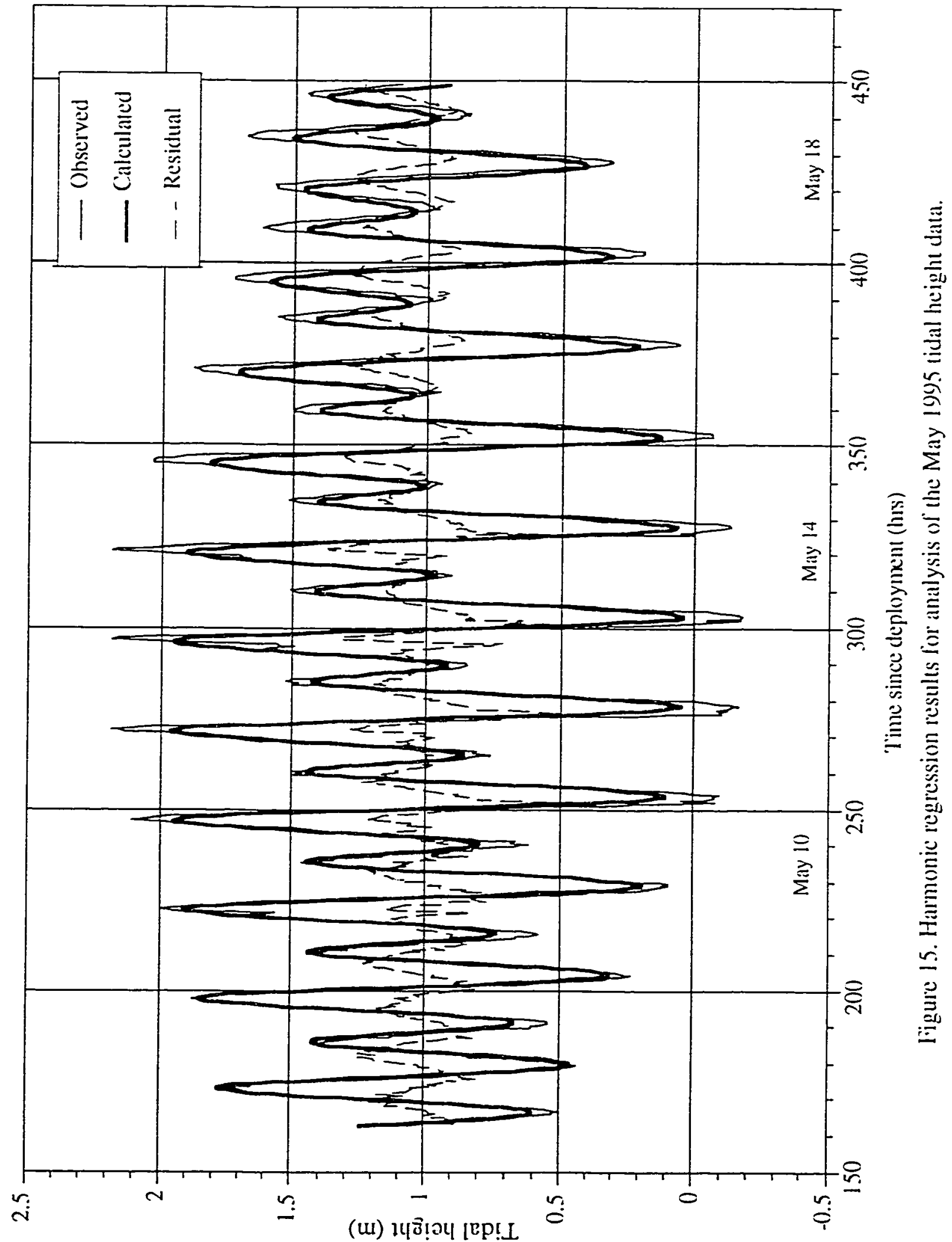



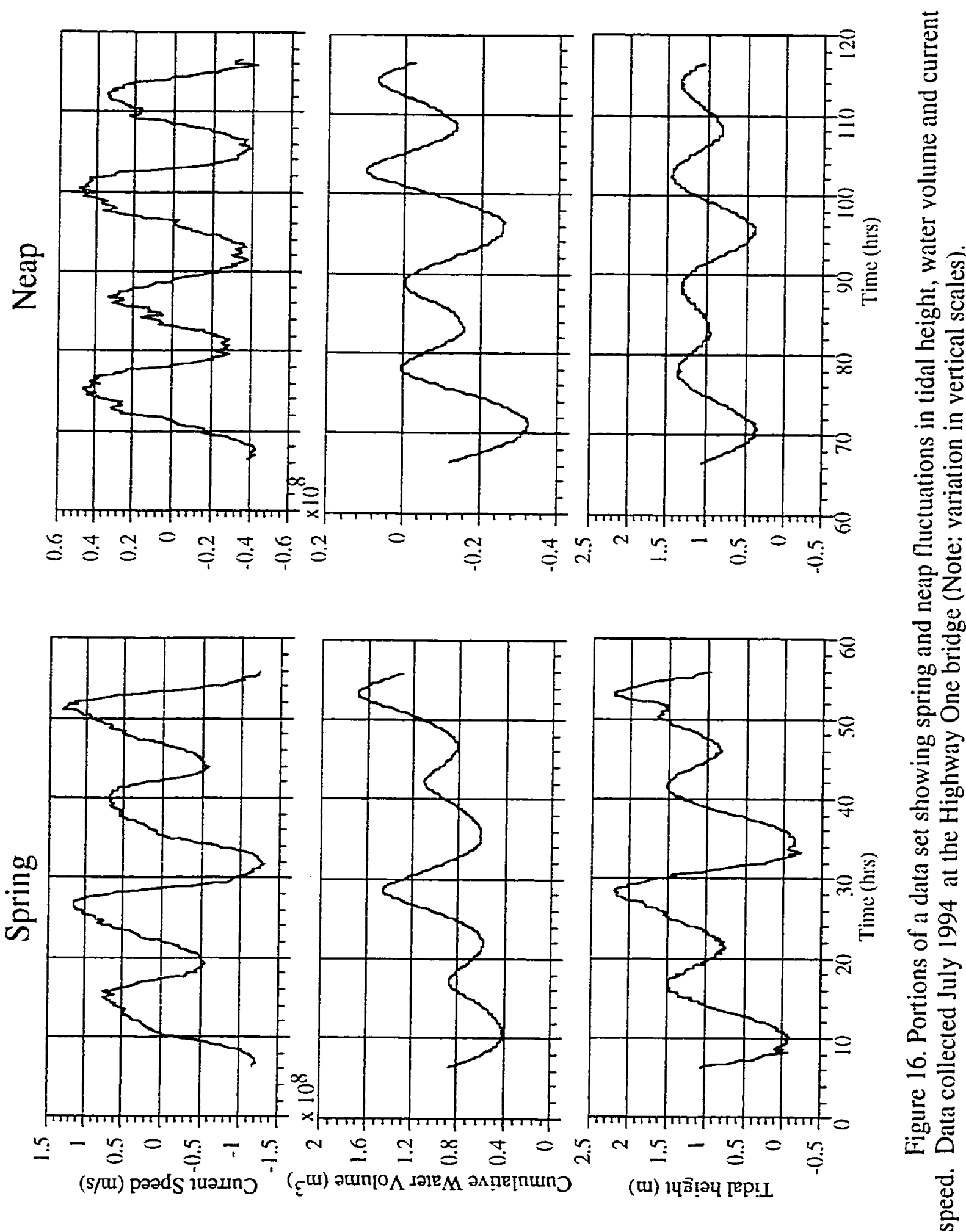
In December of 1993, the total water volume calculated for Elkhorn Slough was $5.5 \times 10^{6}$ $\mathrm{m}^{3}$ at MLLW. Due to dike and levee breaches, $43 \%$ of the volume at MLLW has been added to the system between 1983 and 1993 (Fig. 17, Table 4). The South Marsh/ Parson's Slough area is responsible for $30 \%$ of this voiume while the Salt Ponds contribute $9 \%$ and the Dolan, North and Bloom/ Porter Marshes each contribute 1 to $2 \%$. Maximum current velocities at the mouth of the slough increased from $0.72 \mathrm{~m} / \mathrm{s}$ to 1.13 $\mathrm{m} / \mathrm{s}$ from 1972 to 1988 (Wong, 1989) and to $1.47 \mathrm{~m} / \mathrm{s}$ in June of 1994 . The timing of these increases partially overlaps with the period of growth in the tidal prism in the slough. Longer periods of flooding establish a large hydraulic head for ebb flow, resulting in ebb currents that reach a maximum of $1.47 \mathrm{~m} / \mathrm{s}$ as opposed to a $1.42 \mathrm{~m} / \mathrm{s}$ maximum current velocities on the flood tide. In summary, these speeds are twice those found by Clark (1972) and are 50\% greater than those reported by Wong (1989).

The water budget for Elkhorn Slough, determined by the integration (equation 9) through a month long deployment, shows an apparent net storage. Data from the May 1995 deployment suggest that $3.1 \times 10^{7} \mathrm{~m}^{3}$ were added to the system in 28 tidal days (equation 9, Fig. 18). This result is erroneous since, to allow for this water volume in Elkhorn Slough, the water surface elevation at the Highway One bridge must rise a total of $3 \mathrm{~m}$ in 28 tidal days. Further analysis shows that the product of $\mathrm{a}+0.04 \mathrm{~m} / \mathrm{s}$ metering error and an average cross-sectional area of $350 \mathrm{~m}^{2}$ integrated over 56 tidal cycles $(2.4 \mathrm{x}$ $10^{6}$ seconds) would lead to this excess water budget.

The direction of flood and ebb currents in straight open channels is theoretically $180^{\circ}$ apart (Speer and Aubrey, 1985). In Elkhorn Slough, data indicate the direction of 


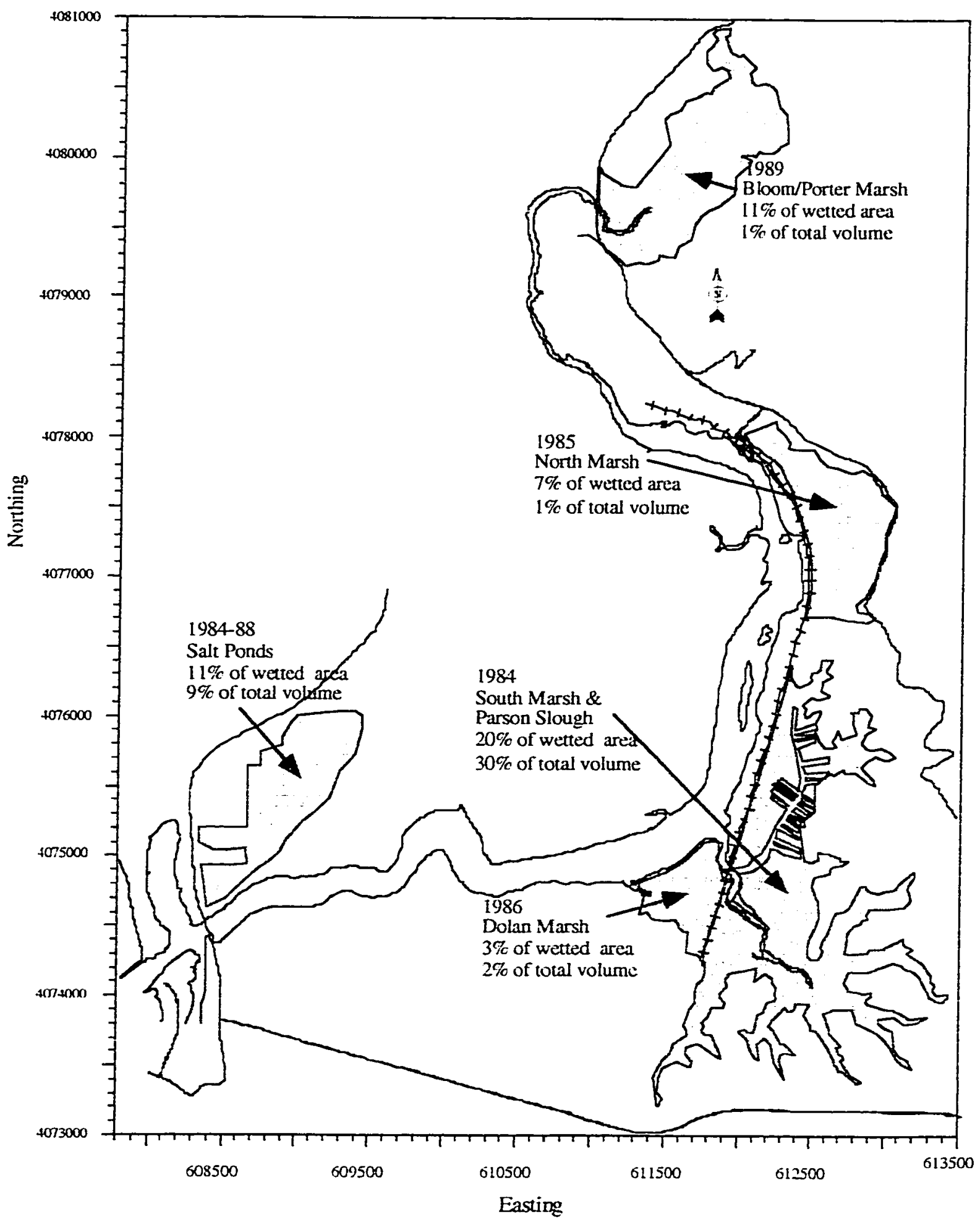

Figure 17. Elkhorn Slough showing recent additions to the total water volume at MLLW and wetted surface area as well as the percent contribution for each to the total slough system (Table 2). Coordinate system: Universal Transverse Mercator, Zone 10. 
Table 4. Recent additions to the Elkhom Slough system contributing to water volume increases and salt water incursion.

\begin{tabular}{|c|c|c|c|c|c|}
\hline \multirow[b]{2}{*}{ Location } & \multirow[b]{2}{*}{$\begin{array}{l}\text { Date of } \\
\text { Saltwater } \\
\text { incursion }\end{array}$} & \multirow{2}{*}{$\begin{array}{c}\text { Surface Area of } \\
\text { Saltwater Habitat } \\
\text { Surface Area } \\
\left(\mathrm{km}^{2}\right)\end{array}$} & \multicolumn{3}{|c|}{$\begin{array}{l}\text { Tidal } \\
\text { Volume }\end{array}$} \\
\hline & & & $\begin{array}{l}\% \text { of Total } \\
\text { Slough } \\
\text { System }\end{array}$ & $\begin{array}{l}\text { Volume } \\
\left(\mathrm{m}^{3}\right)\end{array}$ & $\begin{array}{l}\% \text { of } \\
\text { Total } \\
\text { Slough } \\
\text { System }\end{array}$ \\
\hline $\begin{array}{l}\text { Bloom/ } \\
\text { Porter Marsh }\end{array}$ & 1989 & 1.0 & 11 & 21,880 & 1 \\
\hline North Marsh & 1985 & 0.6 & 7 & 52,622 & 1 \\
\hline $\begin{array}{l}\text { Parson's } \\
\text { Slough/ } \\
\text { South Marsh }\end{array}$ & 1984 & 1.8 & 20 & $1,633,240$ & 30 \\
\hline Dolan Marsh & 1986 & 0.3 & 3 & 131,400 & 2 \\
\hline Salt Ponds & $1984-1988$ & 0.6 & 11 & 507,820 & 9 \\
\hline Totals & & 4.3 & 48 & $2,346,962$ & 43 \\
\hline $\begin{array}{l}\text { Elkhorn } \\
\text { Slough and } \\
\text { Adjacent } \\
\text { Tributaries }\end{array}$ & & 9.1 & 100 & $5,552,920$ & 100 \\
\hline
\end{tabular}




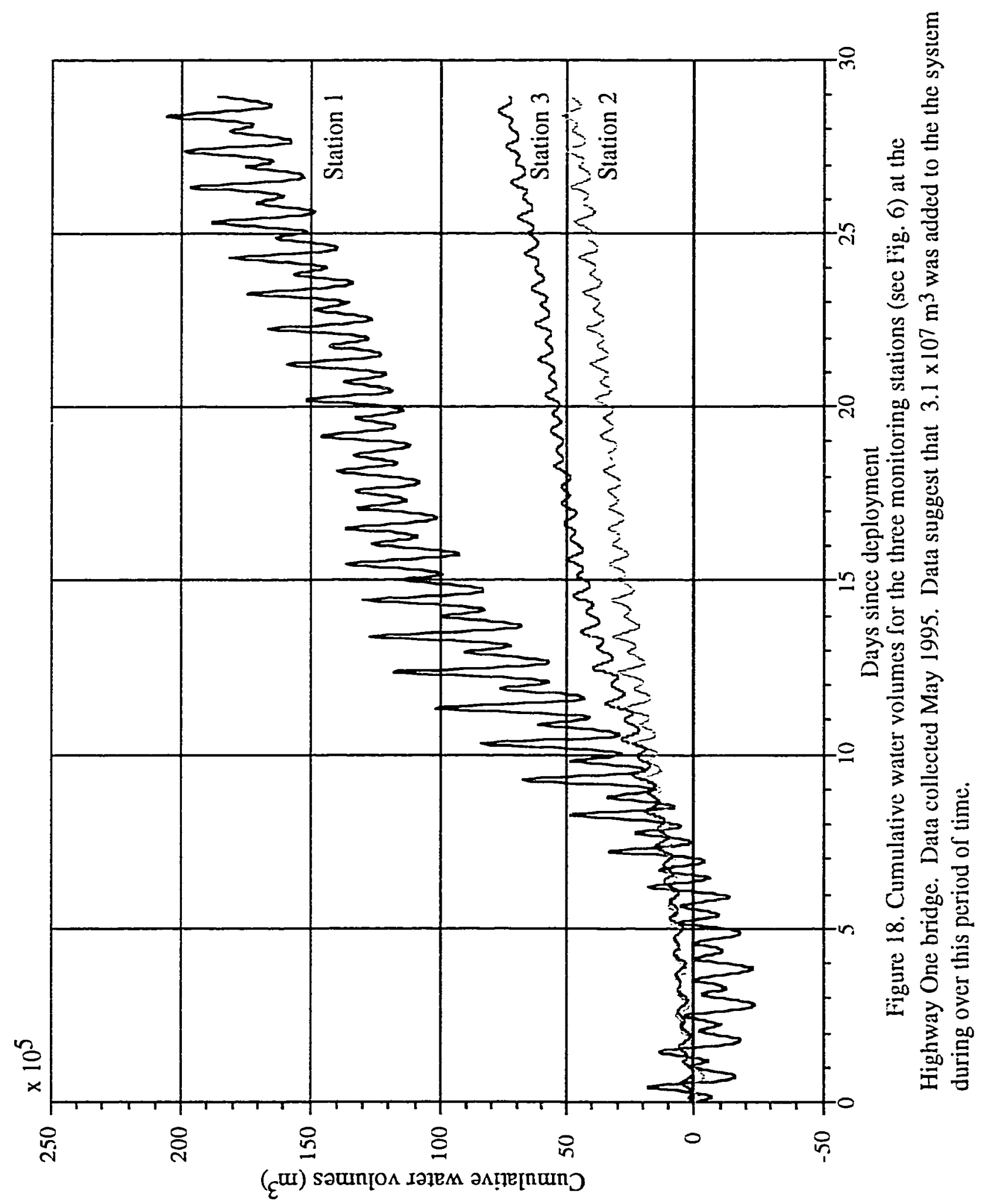


the flooding current to be $188^{\circ}$ away from the direction of the ebb (Fig. 19). Analysis of the bathymetric survey data indicates that this represents the difference in the orientations of the harbor mouth channel versus the lower slough channel. As a result, landward flows into Elkhorn Slough are amplified towards the northern bank in the lower slough thereby introducing a bias in current velocity data obtained from station 1 at the slough entrance. Of the three stations metered, station 1 exhibited the highest velocities and accounted for the largest amount of calculated water and material transport in the slough.

Therefore, the preceding errors combine to produce an overestimate in the magnitude of flooding currents at the Highway One bridge.

\section{Suspended Sediment Transport}

Current and turbidity profile results at the slough entrance show little variation with depth. The current meter profiling indicates that the average flow speed in the channel takes place at depth of $2.25 \mathrm{~m}$ below MLLW at station 1 (Fig. 20). Deployments at this position during April, July and November 1994 produced the data sets with the least amount of scatter. Tidal ranges during the three months were similar; 0.70 to $0.85 \mathrm{~m}$ and 1.19 to $2.5 \mathrm{~m}$ for neap and spring tides, respectively. Sampling time was biased towards spring tidal conditions ( 165 out of 235 sampling hours) to focus on the most extreme changes in tidal heights and currents. These current and turbidity measurements show a net sediment transport out of the slough on the order of 3 to $5 \mathrm{x}$ $10^{4} \mathrm{~kg}$ per tidal cycle (i.e., in Figure $21,7.6 \times 10^{5} \mathrm{~kg} / 16$ tidal cycles $=4.8 \times 10^{4} \mathrm{~kg}$ per tidal cycle). If these daily estimates are indicative of the yearly average, the annual loss 


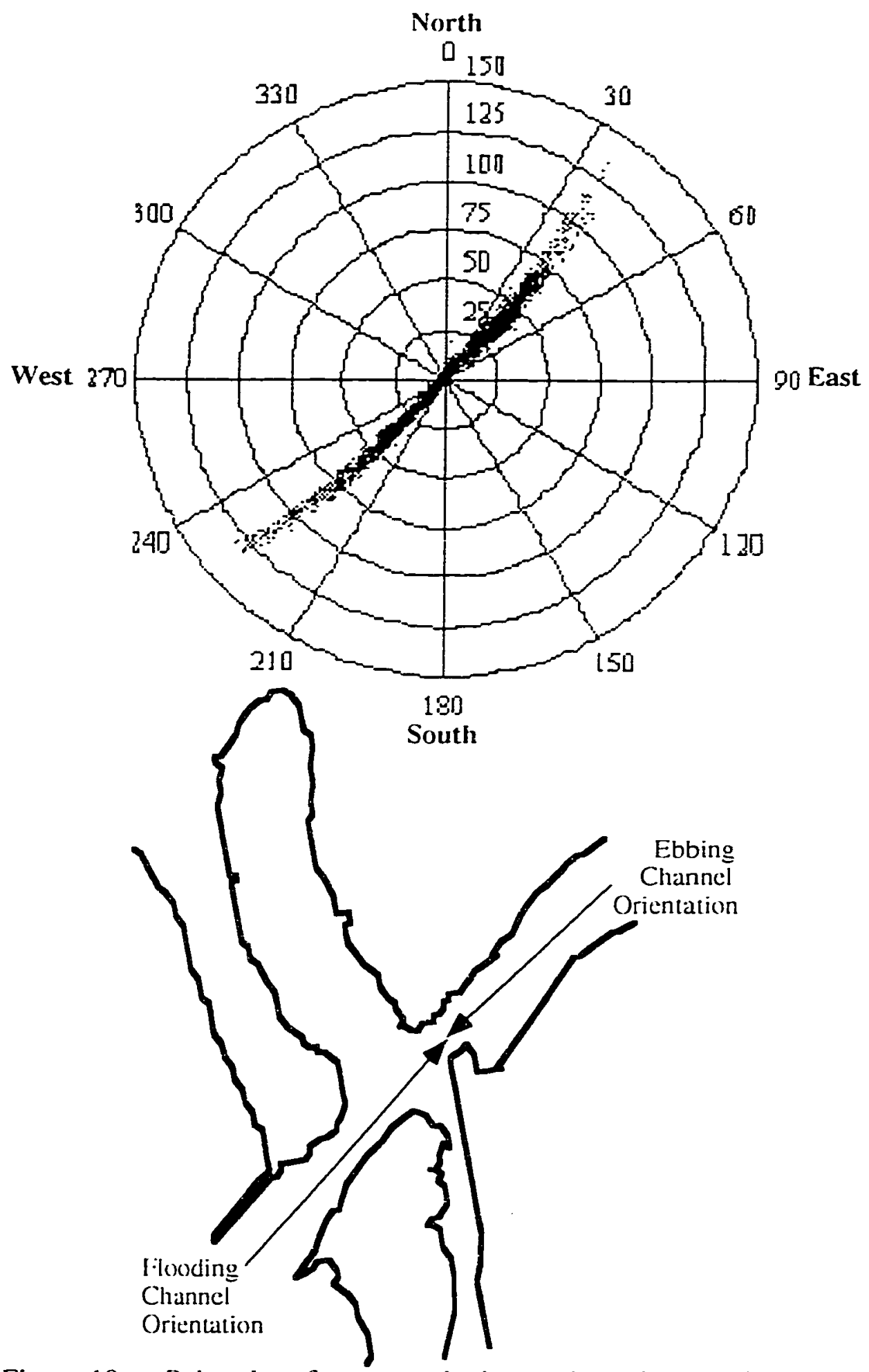

Figure 19. a) Polar plot of current velocity $(\mathrm{cm} / \mathrm{s})$, values on the vertical axis, as a function of llow direction. Values plotted to lower left represent ebb flow and values to the upper right represent the flood. b) Map of the lower slough with vectors indicating the different directions for water flow. All values are relative to magnetic north. 


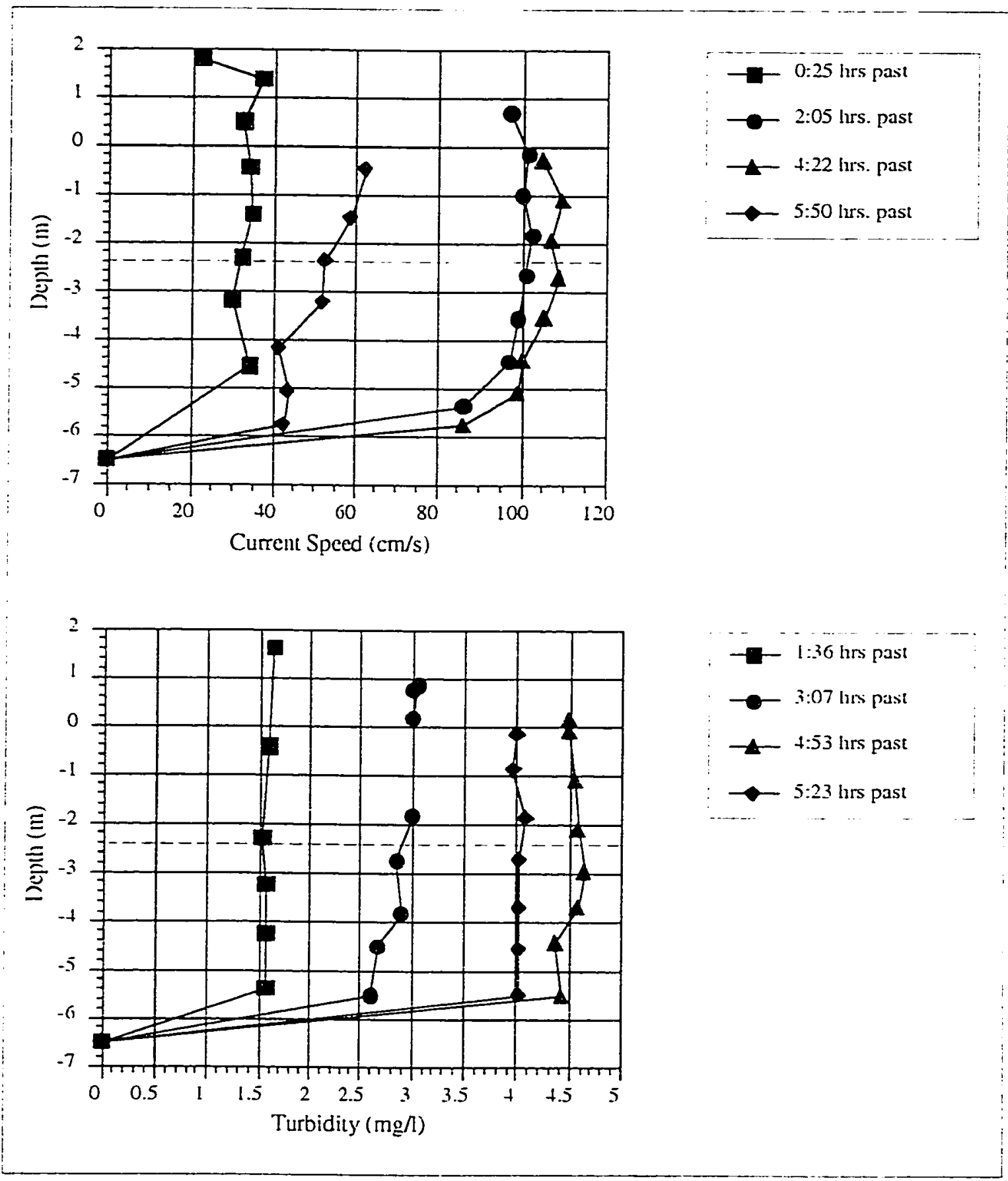

Figure 20. Top: Current velocity profiles at the mouth of Kilkhorn Slough on 8 Feb 94. Bottom: Turbidity proliles at the mouth on $10 \mathrm{Dec} .93$. Values in the legend represent time since high tide. Dashed line represents depth of average flow speed. 


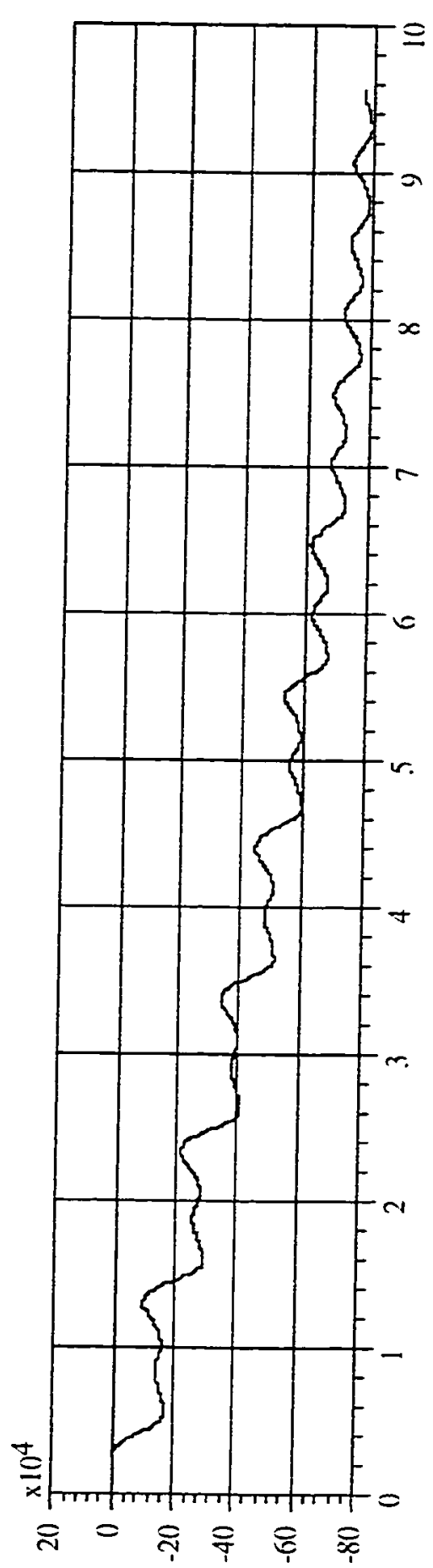

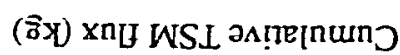

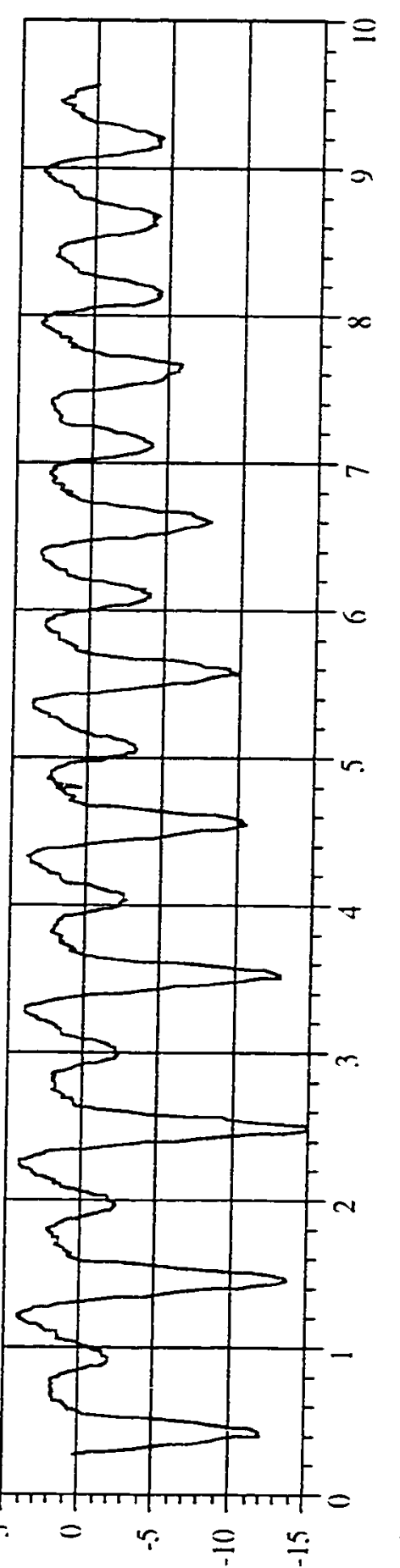

(s/ôy) Lodsuren WSI

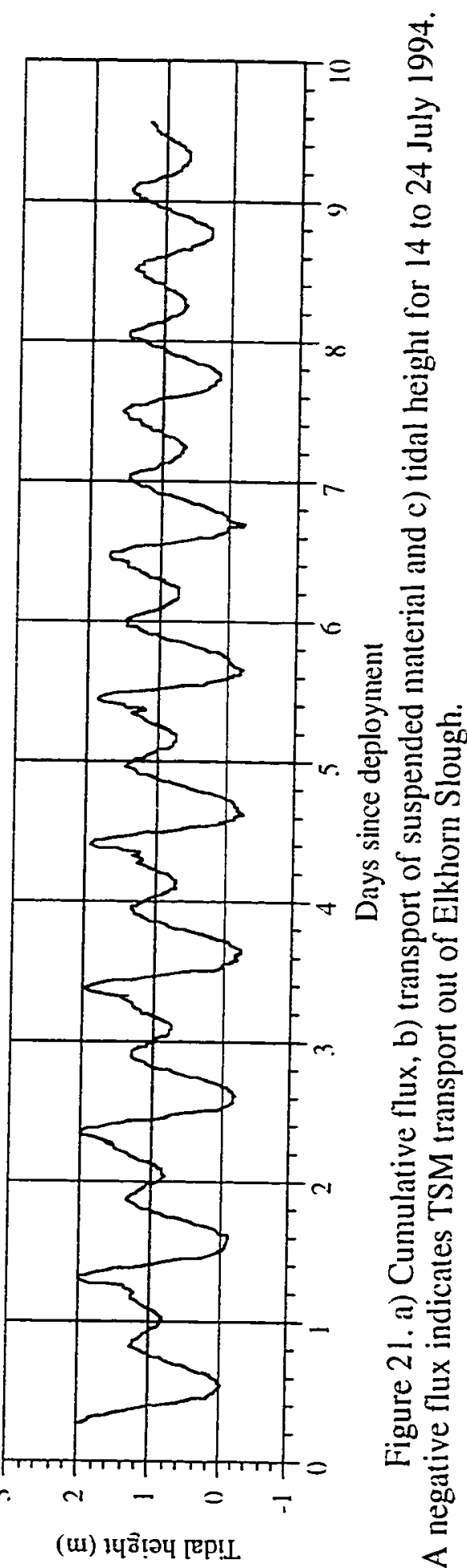


of suspended sediment from Elkhorn Slough is 1 to $3 \times 10^{7} \mathrm{~kg}$. However, the same combination of errors that result in flooding currents to appear faster than the actual velocities (as outlined in the previous section), will cause estimates of outgoing or negative sediment fluxes in this study to be conservative and the losses estimated should be considered minimum values. These errors can be avoided in future studies by deploying a denser array of current meters across the mouth of Elkhorn Slough, which would assign a smaller cross-sectional area to each current meter, thereby improving the resolution of the data.

\section{Erosion Rates}

The rates of erosion between 1988 and 1996 can now be quantified within the general locales in Elkhorn Slough (lower slough, middle slough, upper slough, tidal creeks and Parson's Slough), their tidal environments (upper intertidal, lower intertidal, and subtidal) and the years in which they were sampled. The lower-intertidal and subtidal erosion rates are based upon measurements taken in 1988 (Oliver et al., in review) and 1993, whereas the upper-intertidal rates are based upon bank erosion measurements collected in 1994 and 1996. Results will first be presented temporally (1988 to 1993 and 1994 to 1996) and then spatially or by region and environment.

Rates based on measurements taken in 1988 and 1993 show that the lowerintertidal region has the greatest erosional loss with the largest rates $\left(8.4 \times 10^{4} \mathrm{~m}^{3} / \mathrm{yr}\right)$ observed in the middle slough region (Fig. 22). The lower slough, upper slough, and Parson's Slough follow, in order from high to low, with net losses observed in all locales. 


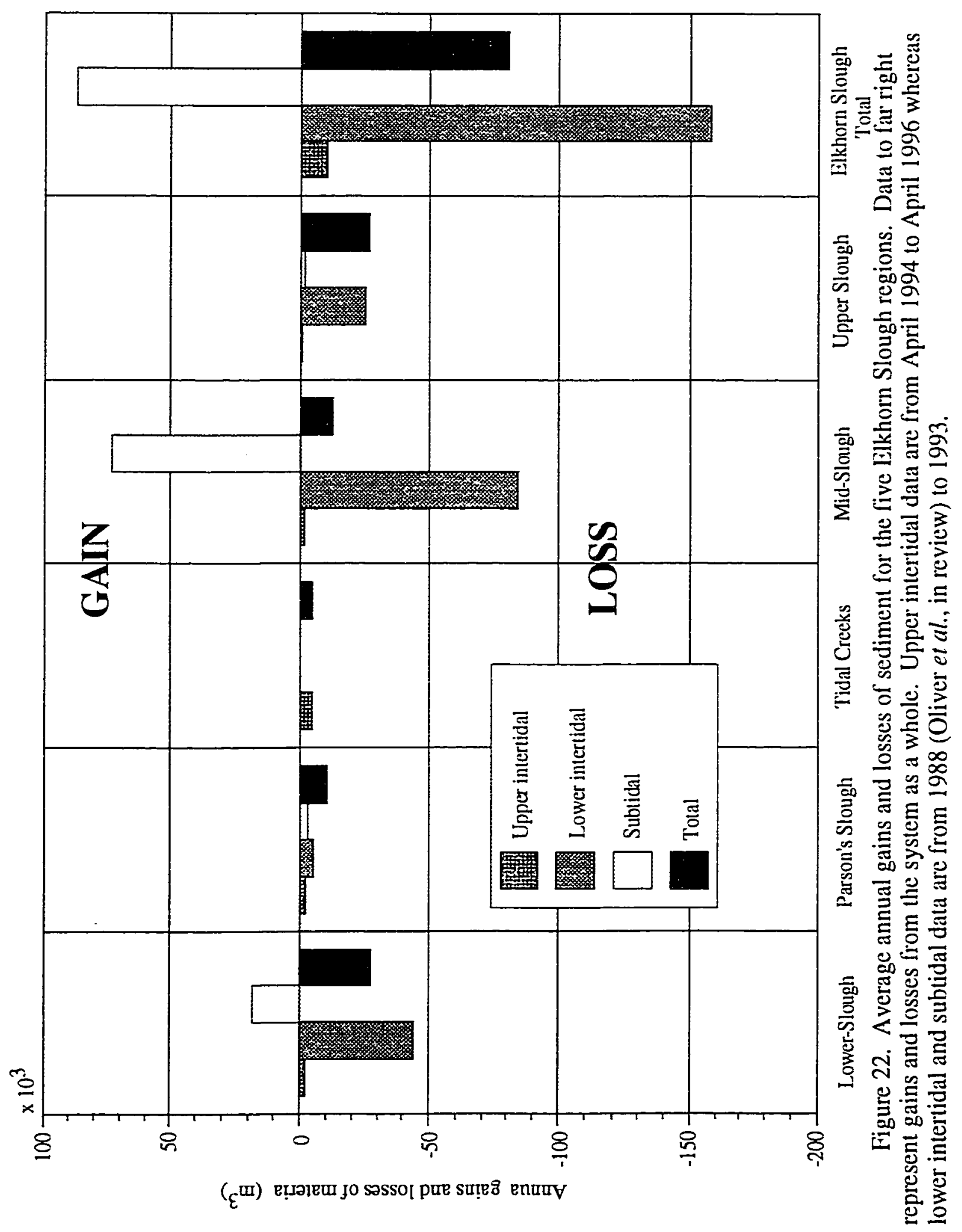


The subtidal zone between 1988 and 1993 shows a net gain of sediment in the lower slough and middle slough regions with deposition rates of $1.8 \times 10^{4} \mathrm{~m}^{3} / \mathrm{yr}$ and $7.3 \times 10^{4} \mathrm{~m}^{3} / \mathrm{yr}$ since 1988. Parson's Slough and the upper slough lost $3.0 \times 10^{3}$ and $1.2 \times 10^{3} \mathrm{~m}^{3} / \mathrm{yr}$, respectively (Fig. 22).

Bank erosion data from April 1994 to April 1996 show the greatest upperintertidal losses $\left(2.2 \times 10^{3} \mathrm{~m}^{3} / \mathrm{yr}\right)$ in the tidal creeks and Parson's Slough regions (Fig. 22). Upper-intertidal losses are also high in the lower slough $\left(1.8 \times 10^{3} \mathrm{~m}^{3} / \mathrm{yr}\right)$ where the greatest vertical loss of sediment was measured (approximately $0.6 \mathrm{~m}$ ). In the upper slough, where bank retreat rates are the most dramatic, net volumetric losses only approach $630 \mathrm{~m}^{3} / \mathrm{yr}$ due to the low values of vertical loss $(\sim 0.17 \mathrm{~m})$.

In summary, between 1988 and 1993, the overall sediment loss from the lowerintertidal area is $1.6 \times 10^{5}\left( \pm 8.0 \times 10^{4}\right) \mathrm{m}^{3} / \mathrm{yr}$ while the subtidal area gained $8.7 \times 10^{4}( \pm$ $\left.4.4 \times 10^{4}\right) \mathrm{m}^{3} / \mathrm{yr}$. Between 1994 and 1996, the upper-intertidal region has lost an average of $1.0 \times 10^{4}( \pm 5,000) \mathrm{m}^{3} / \mathrm{yr}$. Collectively, the average annual loss estimated from these three environments is $8.0 \times 10^{4}\left( \pm 4.0 \times 10^{4}\right) \mathrm{m}^{3} / \mathrm{yr}$ (Fig. 22). 
DISCUSSION

The opening of the Moss Landing Harbor mouth in 1947 allowed for tidal currents in the Monterey Bay to flow directly into Elkhorn Slough. The fact that large amounts of water from the open ocean are allowed to flow into a narrow inlet is reason enough to expect strong tidal currents at the channel opening (Sverdrup et al., 1942). Since then, the geomorphology of Elkhorn Slough has been observed by long-term residents in the area to have changed dramatically over the past 50 years, thus providing evidence for an erosion problem (person. comm. Charlie Vierra). Wong (1989) documented changes in the hydrology based on comparisons of his study to those of Clark (1972) and Smith (1973). The following discussion will outline the geomorphological and hydrological changes and their significance to the future of Elkhorn Slough.

\section{Tidal Observations}

The tides in Elkhorn Slough are standing wave in character; with a rising tide, flooding currents flow up the channel and reverse as ebbing currents flow out. Clark (1972) showed that the maximum tidal current velocity for a given ebb or flood cycle is proportional to the rate of change of water level expressed as the ratio $\mathrm{dH} / \mathrm{dT}$. Maximum velocities are attained during the midpoint of ebb flow. This is the time of the greatest rate of change in water level $(\mathrm{dH} / \mathrm{dT})$ during which water is passing through an 
equilibrium position in the nodal point or the portion of the tidal wave with the greatest slope (midway between the trough and the crest) (Clark, 1972).

Tidal observations in Elkhorn Slough show higher water levels at the completion of a flooding tide in the upper slough $(\sim 2 \mathrm{~cm}$ average $)$ than at the entrance. These results agree with the NOS 1978 tidal survey, which showed higher tidal elevations at Kirby Park than at the Highway One bridge. Studies of tidal dynamics in shallow-water embayments by Speer and Aubrey (1985) document increases in tidal height due to inward shallowing and narrowing. The magnitude of the elevation difference is controlled by the ratio of surface area to tidal height. As tidal waters flow inland through an estuarine system with a decreasing surface area, tidal flooding will be constricted to a smaller cross-sectional area, thereby producing a rise in water level (Speer and Aubrey, 1985; Friedrichs and Aubrey, 1988). The slightly higher elevation at the slough's headwaters will then provide a hydraulic head for ebbing flow. This effect, combined with the fact that the lower-low tide follows the higher-high tide on the eastern Pacific coast and not vice versa, likely accounts for the maximum tidal current velocities in the ebbing direction.

\section{Temporal Changes in Hydrology}

Temporal changes in maximum tidal current velocities can be examined by plotting the maximum along-channel tidal current velocity (Umax) versus $\mathrm{dH} / \mathrm{dT}$ for the data of Clark (1972), Wong (1989) and for this study (Fig. 23). General trends from the linear regressions show an increasing slope (ratio of $\mathrm{dH} / \mathrm{dT}$ vs. Umax) from 1972 to 


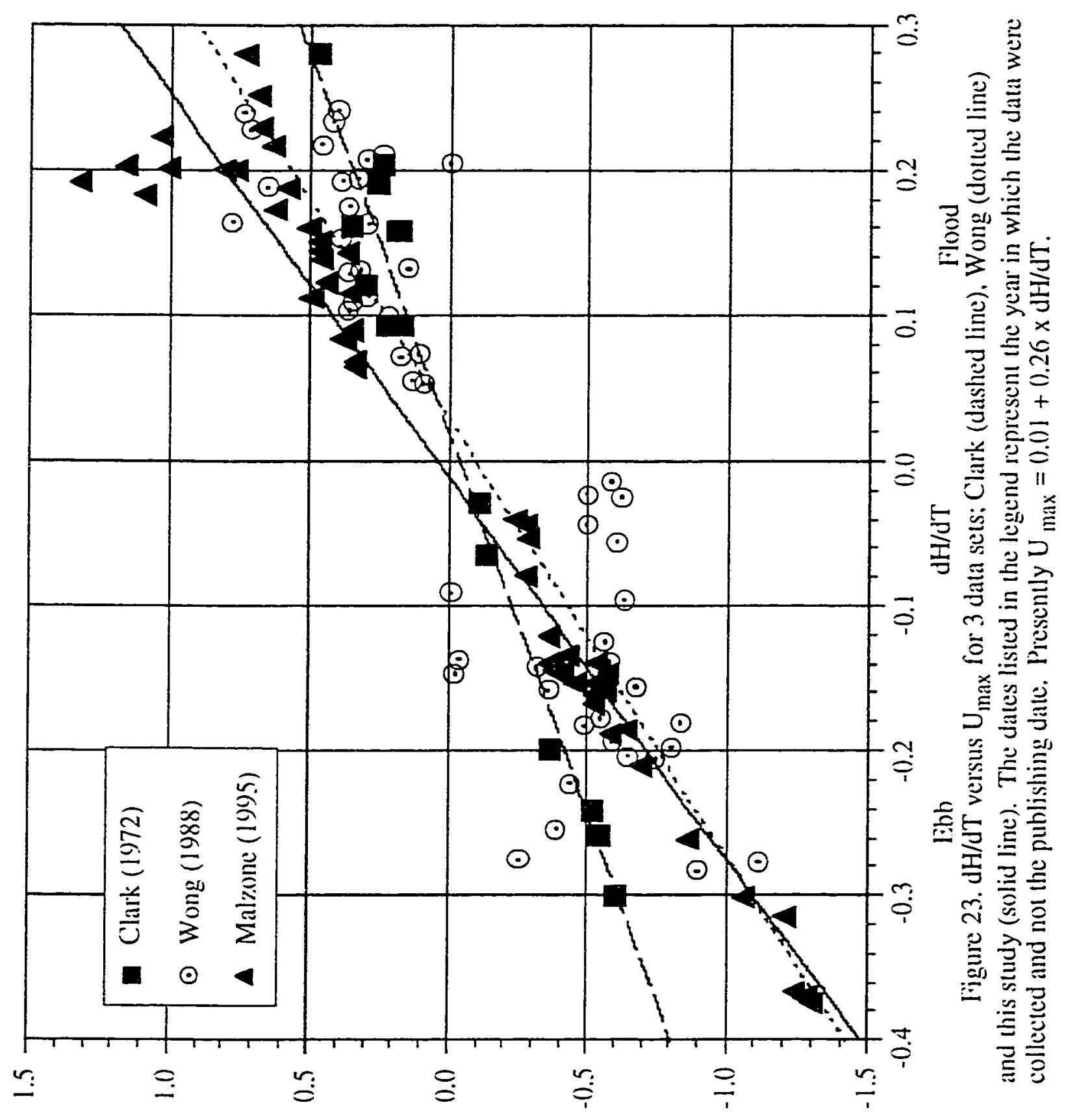

$(s / u) \cdot x e u 1 \Omega$ 
1995. An increasing slope with time indicates that Umax is proportionally increasing for a given value of $\mathrm{dH} / \mathrm{dT}$. In addition, from 1972 to 1988 , increases in the tidal current maximum speed took place on the average of $0.03 \mathrm{~m} / \mathrm{s}$ per year. From 1988 to 1995 , this factor itself has increased to $0.05 \mathrm{~m} / \mathrm{s}$ per year. These changes span a portion of the time, from 1983 to 1995 , in which the total water volume at MLLW increased at a rate of $2.0 \mathrm{x}$ $10^{5} \mathrm{~m}^{3} / \mathrm{yr}$. The increase in the total water volume may be causing more water to occupy the headwaters of Elkhorn Slough over time and should be the subject of future studies.

Increases in the total water volume may also produce greater flooding velocities at the entrance to Elkhorn Slough. Clark (1972) and Wong (1989) reported velocities of 0.5 and $0.7 \mathrm{~m} / \mathrm{s}$, while flooding current speeds were recently observed at $1.42 \mathrm{~m} / \mathrm{s}$. The greater flooding velocities can be explained by the $30 \%$ increase in tidal prism that must be filled in the same 6-to 8-hour period of flooding as observed in the slough (Clark, 1972) prior to the 1983 restoration of Parson's Slough. During a flooding tide, tidal elevations will be higher in the open ocean than at the channel mouth, causing seawater to flow downhill into Elkhom Slough. Recent additions to the total water volume have increased the water flux into Elkhorn Slough, which has augmented flooding currents over the past decade.

\section{Sedimentology and Erosion}

An understanding of the changes to the geomorphology may be attained by looking at the four slough regions, each of which can be subdivided into their 3 tidal environments. Comparisons of sediment analyses, bathymetry, and bank erosion data 
show that lower densities and higher porosities are indicative of areas subject to greater amounts of erosion (Figs. 13 and 22). The lower-intertidal and subtidal sediments in the upper slough are very porous ( $>15 \%)$ and moderately dense $\left(1.1\right.$ to $\left.1.16 \mathrm{~g} / \mathrm{cm}^{3}\right)$, allowing for water to permeate, weaken the cohesiveness of the sediment and produce a loosely consolidated, erodable surface layer. Rates of tidal scour are high in the upper slough where established marsh banks in the lower-intertidal zone are not common.

The middle slough and lower slough show overall morphological changes, such as infilling of the main channel and the establishment of broad mudflats, that suggest that these areas serve as temporary sinks for redeposited material from the upper slough (Fig. 10). The subtidal and lower-intertidal sediment samples acquired in the middle slough and lower slough (transects S4 to S2) are less porous, more dense, and better sorted than sediment sampled in the same tidal environments in the upper slough (Fig. 13). Upperintertidal marsh sediment in the lower slough, at transect S1 (Fig. 4), is partially anthropogenic and poorly sorted resulting in higher porosities $(>25 \%)$ and greater susceptibility to erosion. Coincidently, upper-intertidal dike and levee breaches due to tidal scour in this region have resulted in the establishment of broad, lower-intertidal mudflats.

The lower-intertidal mudflats in the middle and upper slough show little variation in sediment density (Fig. 13). This environment is composed of material eroded from the marsh plain and may be better sorted than sediment from either the main channel or upper intertidal. Sediment porosity differences between lower-intertidal regions in the slough may be due to subtle differences in local hydrology and sedimentation. For 
example, slower current velocities or lower energy conditions (i.e., less mixing) near the headwaters allow for fine-grained suspended material to settle to the slough bottom producing unconsolidated, moderately dense sediments.

\section{Evolution in Slough Morphology}

Determining the future of the slough can be accomplished by looking at the present morphology, and by estimating rates of erosion and the amount of surface area available for erosion. Based on studies of channel width adjustment, the combined processes of scour and fill conserve energy through the formation of deeper, wider channels with decreased bathymetric slopes or uniform energy gradients (Chang, 1985) (Fig. 24). The formation of a narrow, deep channel is first effective in reducing the slope locally along the channel due to decreased boundary resistance and lowered bed elevation. The cross-section that subsequently develops (D in Fig. 24) is semi-circular in shape, which will conserve energy due to its optimum hydraulic geometry (Chang, 1985). A channel undergoing fill, such as the one illustrated in Figure 24, has a rising bed elevation which, also acts to decrease the energy gradient (Chang, 1985). Both scour and fill processes can thus act to conserve energy and are seen in the changes taking place to the channel morphology of Elkhorn Slough. Since 1947, cycles of scour and fill at the slough entrance have resulted in the maximum depth increasing from $1.5 \mathrm{~m}$ to $6.5 \mathrm{~m}$ (MLLW) and the width from $30 \mathrm{~m}$ to $150 \mathrm{~m}$ (Philip Williams and Associates, 1992). Comparisons of results from this study to those acquired by Oliver et al. (in review) in 

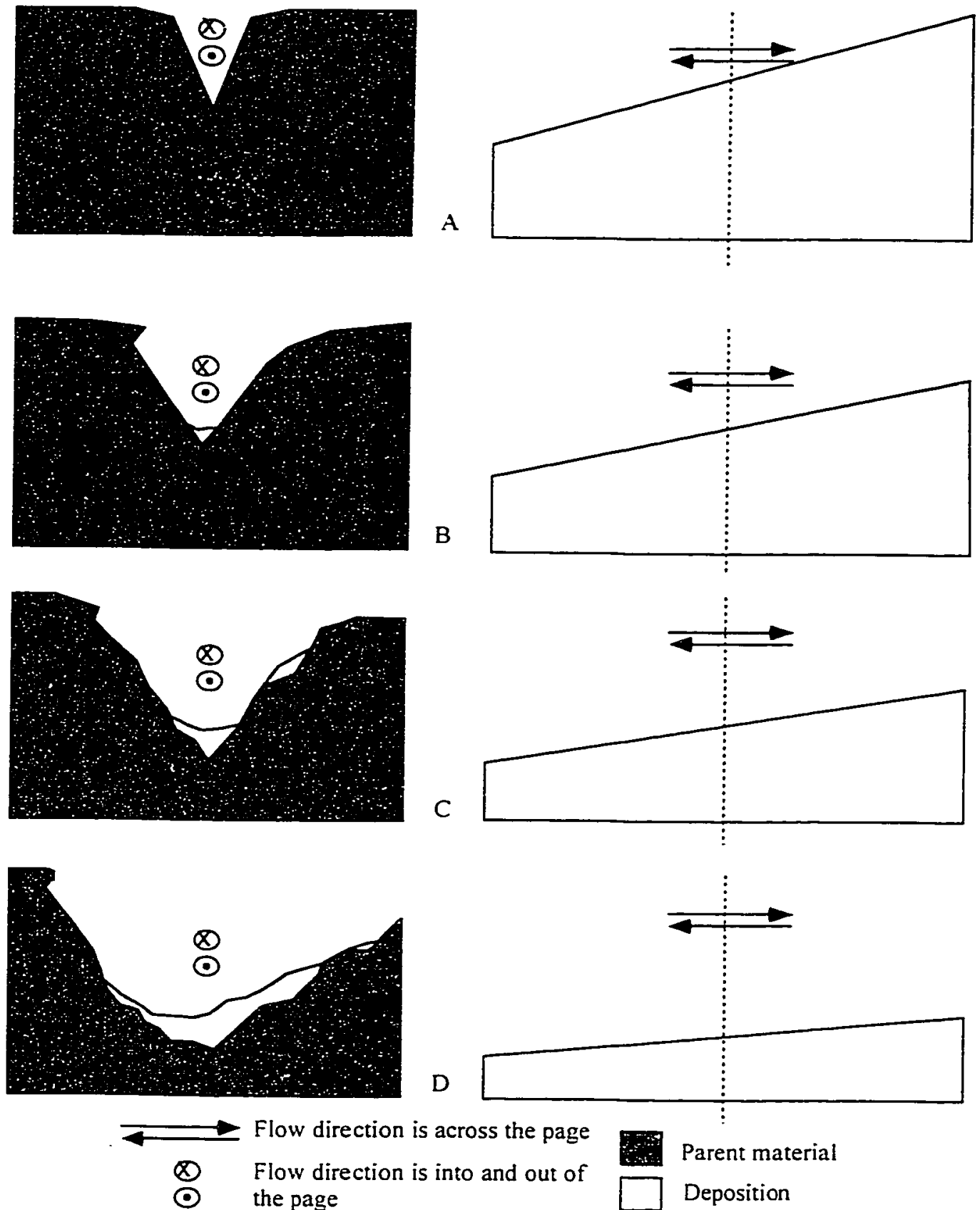

Parent material

Deposition

Figure 24. Illustration of channel adjustment to scour and fill. A small, narrow channel $(A)$ with a steep gradient begins to undergo scour. Scour and deposition of eroded sediments (B) in the channel decreases the bathymetric gradient. Channel scour continues $(C)$, drastically undercutting the bank on one end while deposition from headward sediments allows for the formation of a tidal flat and a semi-circular shaped main channel. Eventually (D), the combination of scour and deposition of headward sediments has led to the formation of a wide channel, extensive tidal flat and a more gentle bathymetric gradient. 
1988 show that, more recently, there has been infilling of sediment (Fig. 10) and the formation of a decreased bathymetric gradient along the channel cross-section near the Highway One bridge. The morphology of the channel at this location has changed from a narrow and constrictive channel to one that is very wide and semi-circular (Fig. 24).

Changes similar to those at the slough entrance are taking place farther inland along the main channel of Elkhorn Slough. The morphology of the main channel is narrow towards the slough's headwaters and constricts water flow (Fig. 10). Erosion is currently widening the channel throughout the length of the slough and the eroded sediment is temporarily redeposited along the main channel in the middle and lower slough. These processes are beginning to produce a uniform morphology in the main channel of the slough, leading to a decreased energy gradient throughout the system.

The areas that may experience the greatest change are those where large surface areas are coincident with erodable sediments, which would include the Salicornia marsh and tidal flats. Erosion in the upper-intertidal regions of these areas is leading to expansion through the development of meandering tidal channels. The surface areas currently available for erosion, namely the upper-intertidal marsh areas, are listed in Table 5. The middle slough and Parson's Slough regions have the greatest surface areas available for erosion. Although erosion rates are high in the upper slough, the surface area available for erosion is small due to the natural constriction caused by the narrowing of Elkhom Valley. 
Table 5. Available erodable surface areas based on location in Elkhorn Slough. Values calculated from photographs.

\begin{tabular}{lc}
\hline$\underline{\text { Location }}$ & Surface Area $\left(\mathrm{km}^{2}\right)$ \\
Lower slough & 0.98 \\
Middle slough & 2.51 \\
Parson's Slough & 1.74 \\
Upper slough & 0.98 \\
\hline
\end{tabular}

Present rates of erosion, deposition and sediment transport suggest that Elkhom Slough is evolving into a shallow-tidal embayment with a smooth bathymetric surface and little vertical relief. Continual loss of the banks in the upper-intertidal area is resulting in temporary deposition of this material in isolated areas in the lower-intertidal and subtidal regions. This situation is leading to the formation of an extended lowerintertidal system with a uniform and gentle slope within Elkhorn Slough. The lower slough presently has average depths (below MLLW) of $5.1 \mathrm{~m}$ in the subtidal and $1.2 \mathrm{~m}$ in lower intertidal. If the present rates of infill of the main channel $(0.23 \mathrm{~m} / \mathrm{yr})$ coupled with vertical degradation rates of the mudflats $(0.22 \mathrm{~m} / \mathrm{yr})$ are indicative of long-term conditions then the average depth for both locales will be $3.1 \mathrm{~m}$ in 9 years. However, this estimate does not take into account the recent establishment of a Zostera marina (seagrass) bed in the lower slough. Sediment has accumulated in the Zostera bed, resulting in shoaling of the channel to a depth of $2.9 \mathrm{~m}$, while depths up- and downstream are 5 and $6.5 \mathrm{~m}$, respectively (Fig. 4). 
Erosion in the slough may be analogous to the formation of gullies in fluvial systems where the downstream base level is lowered (Philip Williams and Associates, 1992). Although the flow volume remains unchanged, the gully headwall moves upstream through primary and secondary channels in successive phases. In tidal systems this process may be amplified by an increase in tidal volume due to bank erosion farther upstream (Philip Williams and Associates, 1992). If the Zostera bed expands laterally and covers a larger surface of the slough channel, it could abate erosion by promoting infilling and therefore preventing upstream downcutting of the main channel. In addition, establishment of Zostera beds in Elkhorn Slough would likely promote the formation of natural sills, which would reduce the speed of tidal currents. Erosion rates throughout the system would also slow, therefore changing the evolution of the slough's morphology.

In the middle slough, the average maximum depths of the channel and mudflats presently are $3 \mathrm{~m}$ and $0.5 \mathrm{~m}$, respectively. Once again, if present rates of erosion are indicative of longterm processes then the average depth for both locations will be $4.4 \mathrm{~m}$ in 35 years. Predictions of morphological changes for the South Marsh area, south of the SPRR trestle, can not be made due to a lack of data. Because the upper slough is a region where subtidal erosion rates exceed those of the lower intertidal, interpretation of these data suggests that these areas will never achieve the same depth, assuming a steady state system.

Similarities of channel cross-sections of the lower- and middle-slough regions suggest that these areas may be approaching comparable geomorphologies. Relative to the average erosion rate for Elkhorn Slough from 1988 to present, the rates of scour in the 
lower and middle slough appear to be slowing while temporary deposition of sediments (eroded from headward regions) in these areas is resulting in decreased surface slopes along the margins of the channel. However, rates of tidal scour in the Parson's Slough and upper slough appear to be increasing. Sediments in these regions are less dense and more porous allowing for greater erosion.

The breakdown of dikes and levees in the slough provides additional water volume to the tidal prism, which exacerbates the scour problem. As of $1992,0.95 \mathrm{~km}^{2}$ were still protected by these structures. Rates of removal of existing dikes and levees can not be predicted, but if the tidal scour persists, all unmaintained water containment structures will be breached and only then may erosion rates approach steady state.

\section{Erosion Rates and Future Sediment Losses}

An average sediment density of $1210 \mathrm{~kg} / \mathrm{m}^{3}$ in Elkhorn Slough was used to convert data obtained from the current meter and the transmissometer ( $\mathrm{kg} / \mathrm{yr}$ to $\mathrm{m}^{3} / \mathrm{yr}$ ) to aid in determining an erosion rate for the slough. From this calculation the total suspended material transport loss (calculated from S4 instrument and transmissometer measurements) is estimated to range from 0.8 to $2.4 \times 10^{4} \mathrm{~m}^{3} / \mathrm{yr}$. Comparison of this estimate to the total material lost from the three separate environments collectively (calculated from bathymetric and bank erosion data to be $8.0 \times 10^{4} \mathrm{~m}^{3} / \mathrm{yr}$ ) shows a discrepancy of a factor of approximately 3 to 10 . The sediment flux measurements associated with this study were made with sampling periods ranging from 3 to 10 days during dry conditions with minor amounts of surface runoff. They do not account for 
episodic events such as large storms and associated storm surge and surface runoff. Therefore, the erosional losses obtained from short-term transport studies are, most likely, not representative of annual losses of suspended sediment from the system. In addition, estimates of bedload and near-bedload transport ( 0 to $1.5 \mathrm{~m}$ above the channel bottom) have not been included in this analysis and may represent larger contributions to the tidal scour problem than originally hypothesized. Finally, the correction for the water budget problem, illustrated by Figure 18, indicates that the July 1994 sediment losses are conservative by approximately $10 \%$ due to the overestimation of flooding tides.

A prediction of future sediment losses from the Elkhorn Slough can be estimated, assuming an erosion rate of $8.0 \times 10^{4} \mathrm{~m}^{3} / \mathrm{yr}$, which represents the collective annual losses of the subtidal, lower-intertidal and upper-intertidal regions throughout the slough (see page 55 ). This erosion rate seems reasonable considering the average annual sediment loss from 1946 to 1993 was $3.5 \times 10^{4} \mathrm{~m}^{3} / \mathrm{yr}$ (Crampton, 1994). It is also noted that estimates based on this number $\left(8.0 \times 10^{4} \mathrm{~m}^{3} / \mathrm{yr}\right)$ may also be conservative due to the fact that bank and subtidal erosion losses were not calculated for the Parson's Slough/ South Marsh area, a region that constitutes $30 \%$ of the tidal volume and has only been subject to tidal scour for 13 years. Magnitudes of erosion and subsequent transport out of this part of the system may be extremely high, but any conclusions must await additional measurements. In addition, due to their extremely shallow depths, tidal creeks have not been surveyed nor monitored for lower intertidal and subtidal erosion. The creeks allow for greater tidal action on the salt marsh and are subject to a substantial amount of tidal scour. 
Presently, approximately $6.24 \mathrm{~km}^{2}$ of surface area is available for erosion, including the Salicornia marsh habitat. Observations of the erosion process indicate that the loss of this habitat takes place at the fringes of the marsh region at the upper limit of the lower-intertidal region. However, as stated above, the rates of loss presented in this thesis are based upon numerical analysis of data collected for this study, which may not encompass all erosional processes within the slough. Losses in this region are taking place at an average rate of $1.58 \times 10^{5} \mathrm{~m}^{3} /$ year. Based on this estimate, to remove a volume equal to $1 \mathrm{~m}$ of vertical loss of the Salicornia marsh habitat, from an elevation of $1.45 \mathrm{~m}$ to $0.45 \mathrm{~m}$ MLLW (i.e., $6.24 \times 10^{6} \mathrm{~m}^{2} \times 1 \mathrm{~m}=6.24 \times 10^{6} \mathrm{~m}^{3}$ ), will take 20 to 60 years. The above calculation is based on erosion rates for only the lower-intertidal region, but sediment losses occur throughout the entire slough. If the average erosion rate for the entire slough system $\left(8 \times 10^{4} \mathrm{~m}^{3} /\right.$ year $)$ is used as the basis for this calculation, then the loss of this habitat may take as long as 40 to 120 years. 
Changes to the geomorphology and tidal character of Elkhorn Slough have been tightly coupled, resulting in an ongoing erosion problem. To understand these changes, the tidal scour processes have been examined from five perspectives to produce a description of sediment sources and budgets in the slough. The critical factor controlling the progression of erosion has been the tidal flow of water in the slough. As tidal height rises, flooding currents approach a maximum of $1.42 \mathrm{~m} / \mathrm{s}$ on spring tides, with water quickly inundating the main channel, tidal creeks and Parson's Slough. Upon reaching a tidal height of approximately $1.5 \mathrm{~m}$, the low-lying marshes become covered with saltwater. At high tide, enough water has made its way into the slough to cause a $0.02 \mathrm{~m}$ higher tide in the upper-reaches relative to the mouth of Elkhorn Slough at the Highway One bridge. After a flood duration of up to 8 hours, the tidal flow reverses and currents flow out, attaining speeds of up to $1.47 \mathrm{~m} / \mathrm{s}$ by mid-tide. Banks are undercut and the sediment is suspended, transported, and redeposited on the lower-intertidal mudflats. Here sediment is temporarily retained, and later transported to the main channel in the subtidal zone and eventually out of the slough at an estimated rate of at least $8.0 \times 10^{4}$ $\mathrm{m}^{3} / \mathrm{yr}$ and possibly higher.

The currents in Elkhorn Slough regulate the amount of material transported in the slough as well as the magnitude of the scour. Since Wong's (1989) studies, current speeds have increased and so it follows that tidal scour in Elkhorn Slough has also increased over the past 5 years. The model for the reshaping of channel morphologies 
(Fig. 24) suggests that erosion rates in the upper slough and Parson's Slough continue to rise. Even though energy gradients have begun to decrease elsewhere in the slough, the increase in erosion at these two regions indicates that the system is not at steady-state conditions.

Establishment of a Zostera bed in the lower slough provides a temporary sediment trap allowing for sediment deposition in the main channel. If Zostera growth continues, it could decrease scour by inhibiting downcutting or "gullying" further up the slough. Future work should focus on the establishment of such natural sediment traps in the slough as well as inhibiting the flow into and out of Parson's Slough, which now accounts for $30 \%$ of the tidal prism.

If losses from the upper-intertidal, lower-intertidal and subtidal environments continue at an average cumulative rate of $8.0 \times 10^{4} \mathrm{~m}^{3} / \mathrm{yr}$, Elkhorn Slough will be a shallow tidal embayment whose primary habitats will be an extensive lower-intertidal mudflat and subtidal main channel in 40 to 120 years. 


\section{REFERENCES CITED}

Austin, R.W., and Petzold, T.J., 1975, An instrument for the measurement of spectral attenuation coefficient and narrow angle volume scattering function of ocean waters: La Jolla, California, University of California, San Diego, Scripps Institute of Oceanography, Visibility Laboratory, Reference 75-25, 51 p.

Broenkow, W. W., in review, Oceanography of Elkhorn Slough: Moss Landing, California, Moss Landing Marine Laboratories, Technical Report, 26 p.

Chang, H.H., 1985, Channel width adjustment during scour and fill: Journal of Hydraulic Engineering - ASCE 111, p. 1368 - 1370.

Clark, L.R., 1972, Long period wave characteristics in Moss Landing Harbor and Elkhom Slough [M.S. Thesis]: San Jose, California, San Jose State University, $73 \mathrm{p}$

Crampton, T.A., 1994, Long term effects of Moss Landing Harbor on the wetlands of Elkhorn Slough [M.S. Thesis]: Santa Cruz, University of California, 81 p.

Easterbrook, D.J., 1993, Surface processes and landforms: New York, New York, MacMillan Publishing Company, 520 p.

Friedrichs, C.T., and Aubrey, D.G., 1988, Non-linear tidal distortion in shallow well-mixed estuaries, a synthesis: Estuarine, Coastal and Shelf Science, v.27, p. $521-545$.

Gordon, B.L., 1974, Monterey Bay Area: Natural history and cultural imprints (2nd edition): Pacific Grove, California, Boxwood Press, 321 p. 
Haltiner, J.P., and Thor, D., 1991, Sedimentation processes in Morro Bay, California: Seattle, Washington, Coastal Sediments '91 Proceedings, Specialty Conference/ Water Resources Division/ASCE, p. 831-845.

MacGintie, G.E., 1935, Ecological aspects of a California marine estuary: American Midland Naturalist, v. 16, p. 629-765.

Malzone, C.M., and Kvitek, R., 1995, Bathymetry, bank erosion and tidal scour in Elkhorn Slough: NOAA technical report, $15 \mathrm{p}$.

Oliv.r, J.S., King, J.A., Homberger, M., Schwartz, D.L., in review, Extensive salt marsh erosion caused by human activities in Elkhorn Slough, California, $26 \mathrm{p}$.

Philip Williams and Associates, 1992, Elkhorn Slough tidal hydraulics erosion study, Technical report prepared for U.S. Army Corps of Engineers, San Francisco District, $34 \mathrm{p}$.

Reilly, P.T., 1978, Phosphate flux in Elkhorn Slough, California [M.S. Thesis]: San Jose, California, San Jose State University, $80 \mathrm{p}$.

Schwartz, D.L., 1983, Geological history of Elkhorn Slough, Monterey County, California [M.S. Thesis]: San Jose, California, San Jose State University, 101 p. Smith, R.E., 1973, The hydrography of Elkhorn Slough, a shallow California coastal Embayment: Moss Landing, California, Moss Landing Marine Laboratories, Technical Publication 73-02, 88 p. 
Speer, P.E., and Aubrey, D.G., 1985, A study of non-linear tidal propagation in shallow inlet/estuarine systems Part II: theory. Estuarine: Coastal and Shelf Science, v.21, p. $207-224$.

Sverdrup, H.U., Johnson, M.W., and Fleming, R.H., 1942, The oceans: their physics, chemistry, and general biology: Englewood Cliffs, New Jersey, Prentice-Hall, $1087 \mathrm{p}$.

Weimer, R.J., Howard, J.D., and Lindsay, D.R., 1982, Tidal flats and associated tidal Channels, in Scholle, P.A, and Spearing, Darwin, eds., Sandstone depositional environments: American Association of Petroleum Geologists Memoir 31, p.191-246.

Wetlands Research Associates, Phillip Williams Associates, Avocet Research Associates, 1996, Bolinas Lagoon management plan update, 151 p.

Wong, C., 1989, Observations of tides and tidal currents in Elkhorn Slough [M.S. Thesis]: San Jose, California, San Jose State University, 108 p. 


\section{NOTE TO USERS}

Oversize maps and charts are microfilmed in sections in the following manner:

\section{LEFT TO RIGHT, TOP TO BOTTOM, WITH SMALL OVERLAPS}

The following map or chart has been microfilmed in its entirety at the end of this manuscript (not available on microfiche). A xerographic reproduction has been provided for paper copies and is inserted into the inside of the back cover.

Black and white photographic prints (17"x 23") are available for an additional charge. 



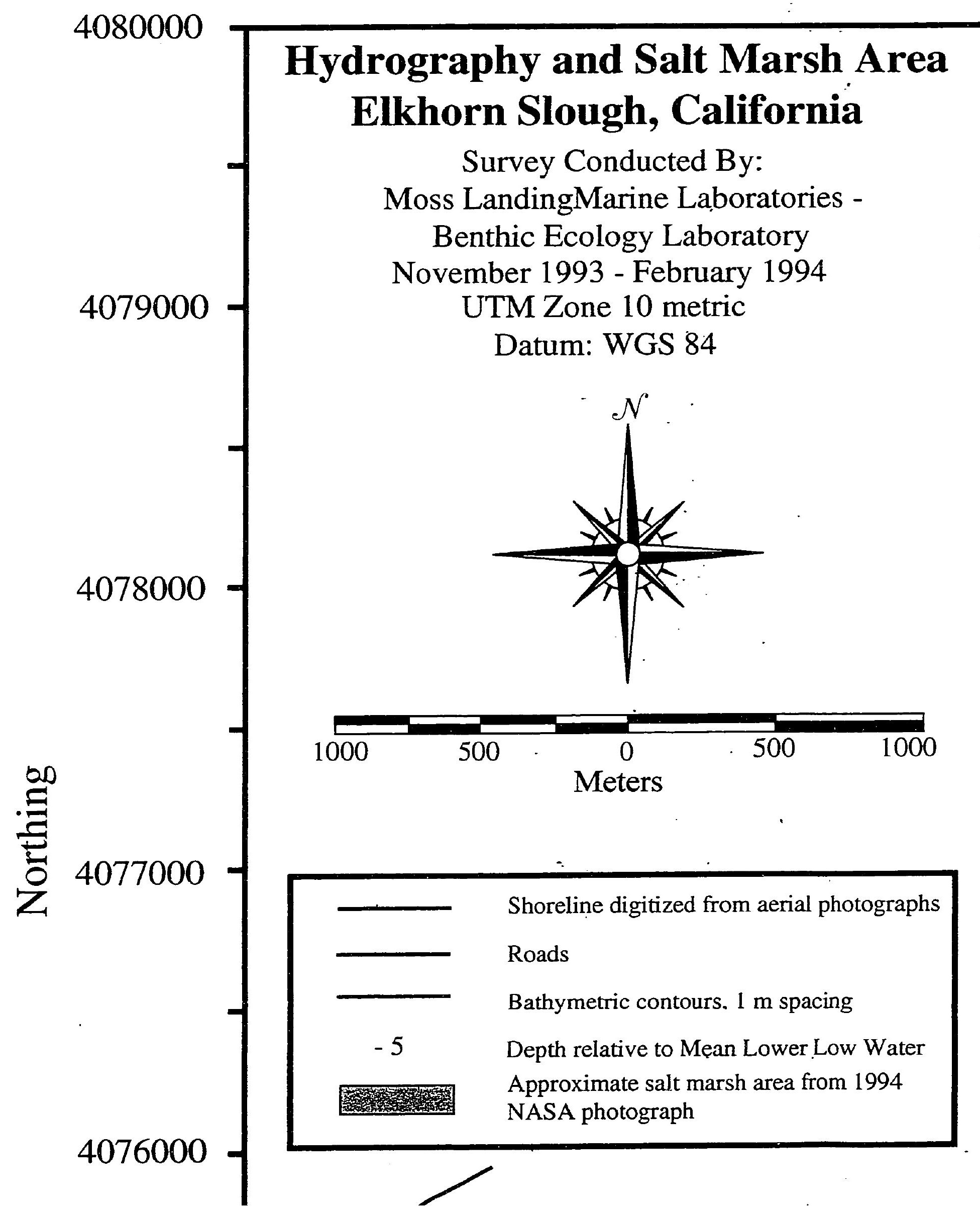




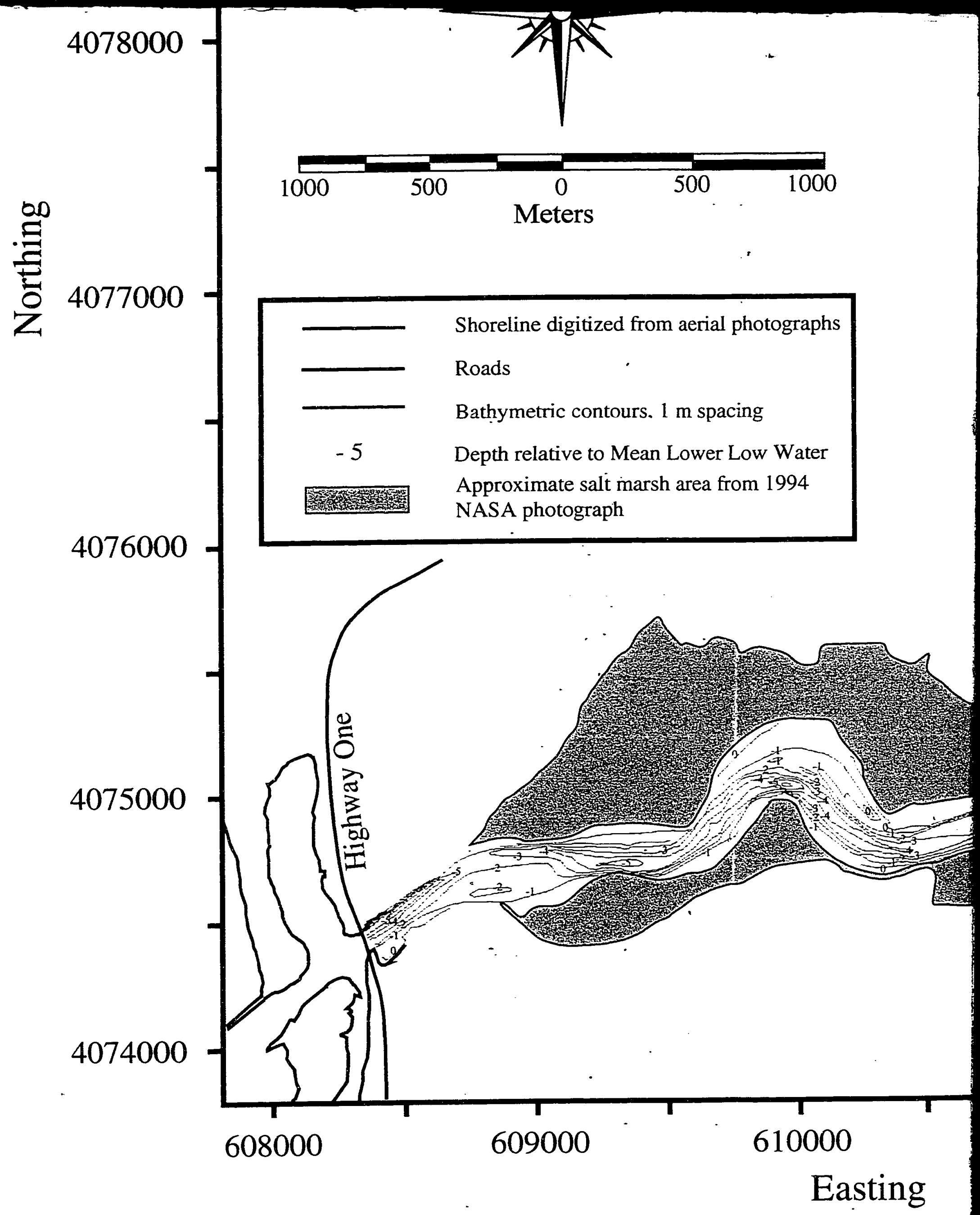




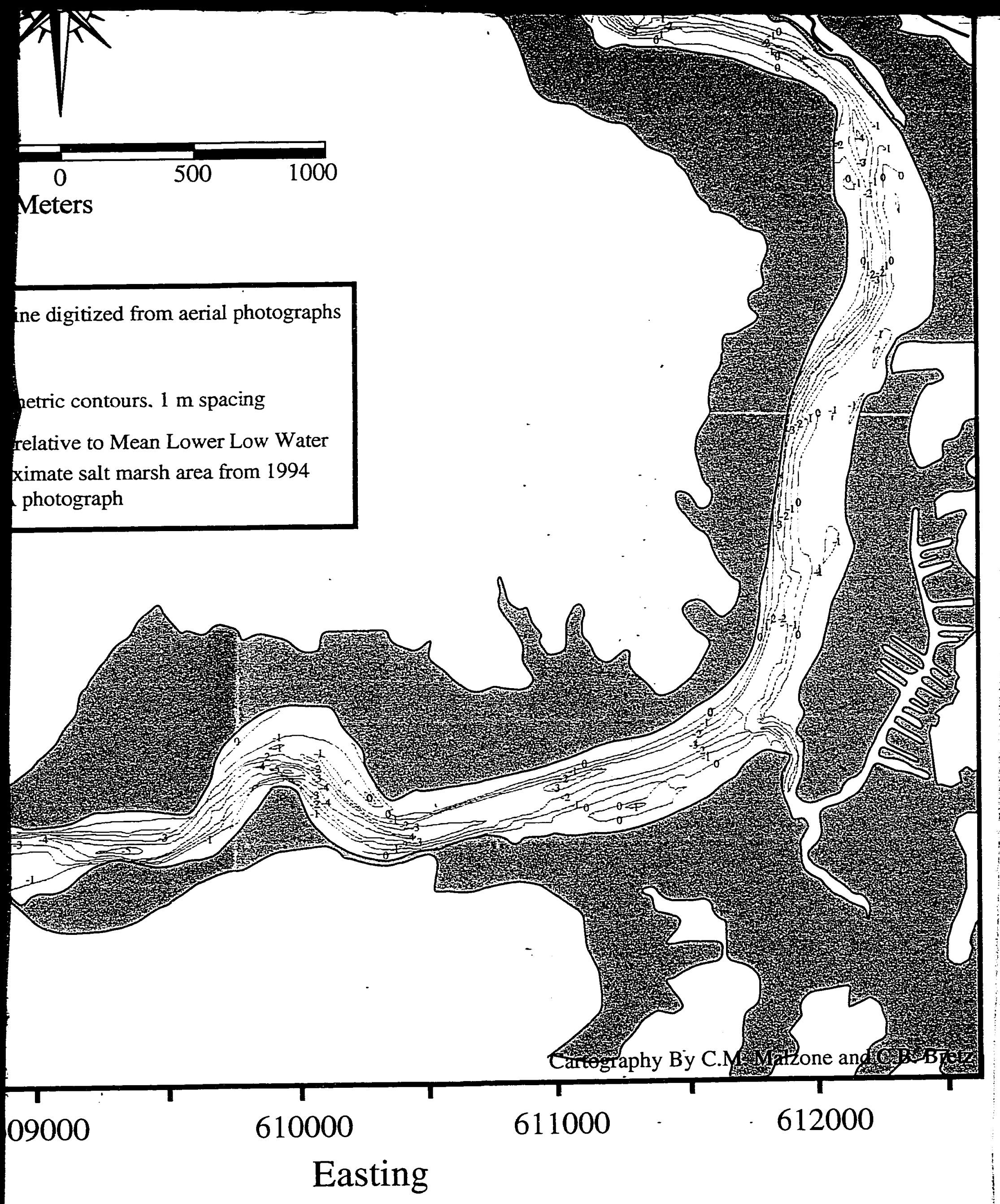



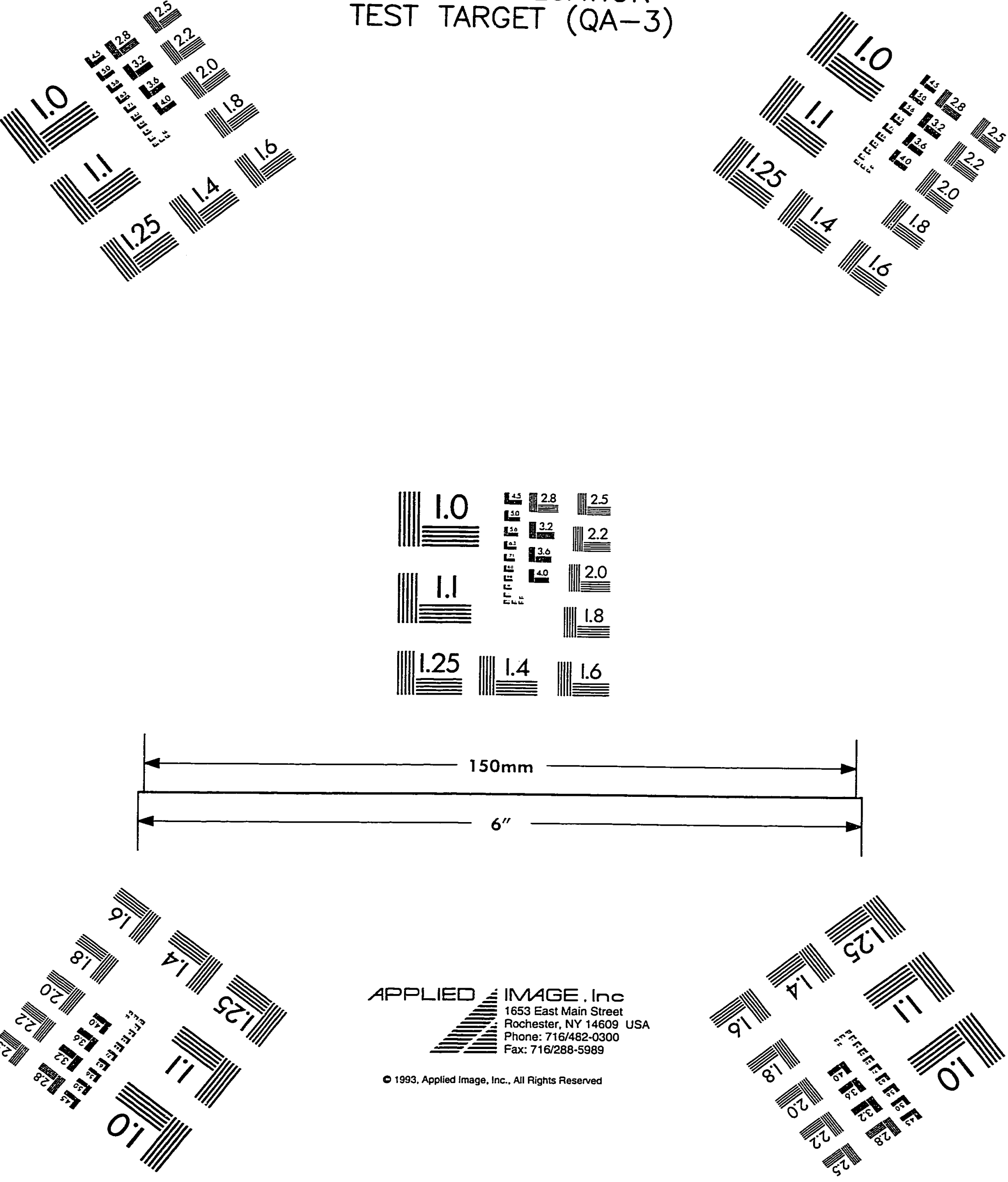